Linköping Studies in Science and Technology

Dissertation No. 1658

\title{
Interface Phenomena in Organic Electronics
}

\author{
Qinye Bao
}

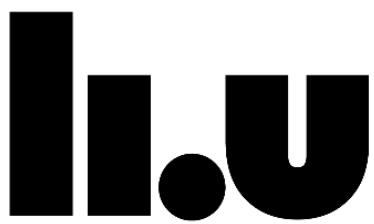

LINKÖPING UNIVERSITY

\author{
Surface Physics and Chemistry Division \\ Department of Physics, Chemistry and Biology (IFM) \\ Linköping University, Sweden
}

2015 Linköping 
Copyright @ Qinye Bao 2015, unless otherwise noted Interface Phenomena in Organic Electronics

$$
\text { Qinye Bao }
$$

ISBN: 978-91-7519-077-8

ISSN: 0345-7524

Linköping Studies in Science and Technology

Dissertation No. 1658

Printed by LiU-Tryck, Linköping, Sweden, 2015 


\begin{abstract}
Organic electronics based on organic semiconductors offer tremendous advantages compared to traditional inorganic counterparts such as low temperature processing, light weight, low manufacturing cost, high throughput and mechanical flexibility. Many key electronic processes in organic electronic devices, e.g. charge injection/extraction, charge recombination and exciton dissociation, occur at interfaces, significantly controlling performance and function. Understanding/modeling the interface energetics at organic-electrode/organic-organic heterojunctions is one of the crucial issues for organic electronic technologies to provide a route for improving device efficiency, which is the aim of the research presented in this thesis.

Integer charge transfer (ICT) states pre-existed in the dark and created as a consequence of Fermi level equilibrium at donor-acceptor interface have a profound effect on open circuit voltage in organic bulk heterojunction photovoltaics. ICT state formation causes vacuum level misalignment that yields a roughly constant effective donor ionization potential to acceptor electron affinity energy difference at the donor-acceptor interface, even though there is a large variation in electron affinity for the fullerene series. The large variation in open circuit voltage for the corresponding device series instead is found to be a consequence of trap-assisted recombination via integer charge transfer states. Based on the results, novel design rules for optimizing open circuit voltage and performance of organic bulk heterojunction solar cells are proposed.
\end{abstract}

Doping and insertion of interlayer are two established methods for enhancing charge injection/extraction properties at organic-electrode interface. By studying the energy level alignment behavior at low to intermediate doping levels for molecule-doped conjugated polymer/electrode interfaces, we deduce that two combined processes govern the interface energetics: (i) equilibration of the Fermi level due to oxidation (or reduction) of polymer sites at the interface as per the ICT model and (ii) a double dipole step induced by image charge from the dopant-polymer charge transfer complex that causes a shift of the work function. Such behavior is expected to hold in general for low to intermediate level doped organic semiconductor systems. The unified model is further extended to be suitable for conjugated electrolyte/electrode interfaces, revealing the design rules for achieving the smallest charge injection/extraction barrier for both thin tunneling and thick charge transporting conjugated electrolyte interlayers.

To probe into the energy level spatial extension at interfaces, we employ the original approach of building and characterizing multilayers composed of a well-defined number of polymer monolayers with the Langmuir-Shäfer method to control polymer film uniformity and thicknesses, avoiding the problems associated with spin-coating ultrathin films. The disordered/amorphous films feature smaller, 
and in fact negligible, energy level bending compared to the more well-ordered films, in contradiction with existing models. It is found that that energy level bending depends on the ICT state distribution rather than the density of states of the neutral polymer chains in relation to the Fermi energy, thus taking into account the Coulomb energy associated with charging the polymer chain and transferring a charge across the interface. Based on this work, a general model for energy level bending in absence of significant doping of conjugated polymer films is proposed.

Organic semiconductors are sensitive to ambient atmosphere that can influence the energetics. The degradation effects of common PCBM film induced by oxygen and water are found to be completely different. Upon exposure to oxygen, the work function is down-shifted by $\sim 0.15 \mathrm{eV}$ compared to the ICT curve of the pristine PCBM film, originating from the weak interaction between the fullerene part of PCBM and oxygen, and this can be reversed by thermal treatment in vacuum. The down-shift in energetics will cause a loss in open circuit voltage at electrode interface, but aids free charge generation at donor-acceptor interface. Upon exposure to water, there is irreversible extensive broadening and bleaching of the valence electronic structure features as well as a substantial decrease of work function and ionization potential, severely degrading the transport properties.

Overall, the research results in this thesis thus give a deeper understanding of interface phenomena in organic electronics, especially regard to organic solar cells, aimed to further improve the device operation efficiency and lifetime. 


\section{Populärvetenskaplig Sammanfattning}

Organisk elektronik baserade på organiska halvledare erbjuder stora fördelar jämfört med traditionella oorganiska material såsom: tillverkning vid låg temperatur, låg vikt, låg tillverkningskostnader, hög produktionstakt och mekanisk flexibilitet. Många viktiga elektroniska processer i organiska elektronik-komponenter, t.ex. laddningsinjektion, laddningsrekombination och excitonseparation, inträffar vid gränsytor och påverkar i hög grad komponenternas funktion och prestanda. Förståelse och modellering av energinivåer vid organisk-elektrod/organisk-organisk heterogena gränsytor är en av de viktigaste frågorna för organisk elektronisk teknik för att driva fram förbättringar inom komponenteffektivitet, vilket är syftet med forskningen som presenteras i avhandlingen. Speciell emfas har lagts på studier av organiska material och gränsytor med relevans för organiska solceller, men många av resultaten har även tillämpningar inom organisk elektronik i stort.

I så-kallade organiska bulk-heterogena solceller, där en blandning av donator- och acceptormaterial i ett lager absorberar ljus och omvandlar ljuset till ström, anses energiskillnaden mellan den håltransporterande nivån i donatormaterialet och den öppenkretsspänningen som solcellen kan generera. Den faktiska öppenkretsspänningen blir dock aldrig så hög på grund av interna förluster, vilka måste minimeras för att uppnå maximal effektivitet i energiomvandlingen. I sen studie visar vi at laddningsöverföring som förekommer i mörker och skapas som en följd av Fermi-nivån jämvikt vid donator-acceptor-gränsytorna i blandlagret har en djupgående effekt på öppenkretsspänningen. För en serie av acceptormaterial i kombination med en donator visar vi att laddningsöverföring orsakar ett potentialsteg vid gränsytorna som ger en $\mathrm{i}$ stort sett konstant energiskillnaden mellan donatormaterialets hål-transporterande nivå och acceptorns elektrontransporterande nivå, även om det finns en stor variation $i$ elektronaffinitet för acceptorserien. Den stora variationen i öppenkretsspänning visar sig istället vara en konsekvens av laddningsrekombination via tillstånd skapade av den "mörka" laddningsöverföringen. Baserat på resultaten från vår studie kan vi föreslå nya regler för att optimera öppenkretsspänning och prestanda av organiska heterogen bulksolceller, vilket framgångsvist testas på en serie av organiska donator- och acceptormaterial.

Doping och användning av ett mellanskikt är två etablerade metoder för att förbättra laddningsöverföring vid organisk-elektrod gränsytor och minimera spänningsförluster. Genom att studera gränsytors elektronstruktur vid låga till medelhöga dopningsnivåer för molekyl-dopade konjugerad polymer/elektrod-gränsytor, kan vi visa att två kombinerade processer styr gränsytornas energinivåupplinjering: (i) jämvikt av Fermi-nivån genom oxidation (eller reduktion) av polymerer vid gränsytan enlig vår generella modell for laddningsöverföring och (ii) ett dubbel-dipolsteg inducerad av spegelladdning från dopmolekyl-polymer laddningsöverföringskomplexet som orsakar ett potentialsteg vid gränsytan. Ett sådant beteende förväntas hålla i allmänhet för låga till medelhögt 
dopade organiska halvledarsystem. Den nya modellen utvidgas ytterligare för att beskriva konjugerad elektrolyt/elektrod gränssnitt, avslöjar regler för att minimera barriärer för laddningsinjektion/extraktion, både för tunna (tunnling) och tjocka (laddningstransport) konjugerade elektrolytmellanskikt.

Ett annan fundamental frågeställning är hur långt ifrån en gränsyta ett potentialfall inducerat av laddningsöverföring sträcker sig. Här använder vi en ny strategi baserad på att bygga och karakterisera multilager med väldefinierade antal polymermonolager deponerade via Langmuir-Shäfer metoden och därmed undvika de oregelbundna och dåligt definierade filmer som är förknippade med spin-beläggning eller förångning av ultratunna lager. I kontrast mot de existerande modellernas förväntningar, så visar oordnade/amorfa filmer mindre, och i själva verket försumbar, utsträckning av laddningsöverföringsområdet, än de mer välordnade filmerna. Resultaten följer väl vår modell för energinivåupplinjering och representerar de första mätningarna av energinivåupplinjering i konjugerade polymerer på väl definierade ultratunna prover.

Organiska halvledare kan vara känsliga för exponering mot luft, då kemiska reaktioner med syre eller vatten kan påverka de laddningstransporterande energinivåerna och därmed komponentfunktion. En vanligt använd acceptormolekyl inom organiska solceller, PCBM, studeras för att klarlägga effekten av syre- och vattenexponering. Våra studier visar att syre och vatten påverkar PCBM lager på helt olika sätt. Vid exponering för syre skiftas arbetsfunktionen nedåt med $\sim 0.15 \mathrm{eV}$ jämfört med "ren" PCBM film, vilket kan ha en negativ effekt på öppenkrets-spänning beroende på val av elektrod, men och andra sidan förbättra generering av fria laddningar vid donator/acceptor gränsytor. Väkelverkan mellan syre och PCBM i filmen är dock svag och effekten kan vändas genom termisk behandling i vakuum. Vatten reagerar kraftigt med PCBM lagret med omfattande förändring av elektronstruktur och minskning av arbetsfunktionen, till skada för komponentfunktion. Denna interaktion är irreversibel så PCBM bör därmed skyddas från vatten under samtliga delar av tillverkningsprocessen och under komponentanvändning. 


\section{List of Publications Included in this Thesis}

1. Trap-Assisted Recombination via Integer Charge Transfer States in Organic Bulk Heterojunction Photovoltaics

Q. Y. Bao, O. Sandberg, D. Dagnelund, S. Sanden, S. Braun, H. Aarnio, X. J. Liu, W. M.

Chen, R. Österbacka, and M. Fahlman

Advanced Functional Materials, 2014, 24, 6309

2. Oxygen- and Water-Based Degradation in [6, 6]-Phenyl-C $61-$ Butyric Acid Methyl Ester (PCBM) Films

Q. Y. Bao, X. J. Liu, S. Braun, and M. Fahlman

Advanced Energy Materials, 2014, 4, 1301272

3. The Energetics of the Semiconducting Polymer-Electrode Interface for SolutionProcessed Electronics

Q. Y. Bao, S. Fabiano, M. Andersson, S. Braun, Z. Y. Sun, X. Crispin, M. Berggren, X. J. Liu, and M. Fahlman

(Submitted)

4. Energetics at Doped Conjugated Polymer/Electrode Interfaces

Q. Y. Bao, X. J. Liu, S. Braun, F. Gao, and M. Fahlman

Advanced Materials Interfaces, 2015, 2, 1400403

5. Regular Energetics at Conjugated Electrolyte/Electrode Modifier for Organic Electronics and Their Implications of Design Rules

Q. Y. Bao, X. J. Liu, E. G. Wang, J. F. Fang, F. Gao, S. Braun, and M. Fahlman (Submitted)

6. Effects of Ultraviolet Soaking on Surface Electronic Structures of Solution Processed ZnO Nanoparticle Films in Polymer Solar Cells

Q. Y. Bao, X. J. Liu, Y. X. Xia, F. Gao, L. D. Kauffmann, O. Margeat, J. Ackermann, and M. Fahlman

Journal of Materials Chemistry A, 2014, 2, 17676 


\section{List of Publications not Included in this Thesis}

1. Correlation Between the Electronic Structures of Transition Metal Oxide-Based Intermediate Connectors and the Device Performance of Tandem Organic Light-Emitting Devices

Q. Y. Bao, J. P. Yang, Y. Xiao, Y. H. Deng, S. T. Lee, Y. Q. Li, and J. X. Tang Journal of Materials Chemistry, 2012, 21, 17476

2. Interfacial Electronic Structures of $\mathrm{WO}_{3}$-Based Intermediate Connectors in Tandem Organic Light-Emitting Diodes

Q. Y. Bao, J. P. Yang, J. X. Tang, Y.Q. Li, C. S. Lee, and S. T. Lee

Organic Electronics, 2010, 11, 1578

3. Electronic Structures of $\mathrm{MoO}_{3}-\mathrm{Based}$ Charge Generation Layer for Tandem Organic Light-Emitting Diodes

Q. Y. Bao, J. P. Yang, Y.Q. Li, and J. X. Tang

Applied Physics Letter, 2010, 97, 063303

4. Role of Thick-Lithium Fluoride Layer in Energy Level Alignment at Organic/Metal Interface: Unifying Effect on High Metallic Work Functions

Z. Y. Sun, S. W. Shi, Q. Y. Bao, X. J. Liu, and M. Fahlman

Advanced Materials interface, 2015, 1400527

5. New Bulk-Heterojunction System for Efficient High-Voltage and High-Fill Factor Solution-Processed Fullerene-Free Organic Photovoltaics

Z. Tang, B. Liu, A. Melianas, J. Bergqvist, W. Tress, Q. Y. Bao, D.P. Qian, O. Inganäs, and F. L. Zhang

Advanced Materials, 2015, DOI: 10.1002/adma.201405485

6. Morphological Control for Highly Efficient Inverted Polymer Solar Cells via the Backbone Design of Cathode Interlayer Materials W. J. Zhang, Y. L. Wu, Q. Y. Bao, F. Gao, and J. F. Fang Advanced Energy Materials, 2014, 4, 1400359 
7. Interplay of Optical, Morphological and Electronic Effects of $\mathrm{ZnO}$ Optical Spacers in Highly Efficient Polymer Solar Cells

S. B. Dkhil, D. Duché, M. Gaceur, A. K.Thakur, F. B. Aboura, L. Escoubas, J. J. Simon, A. Guerrero, J. Bisquert, G. G. Belmonte, Q. Y. Bao, M. Fahlman, C. V. Ackermann, O. Margeat, and J. Ackermann

Advanced Energy Materials, 2014, 4, 1400805

8. Improving Cathodes with a Polymer Interlayer in Reversed Organic Solar Cells Z. Tang, W. Tress, Q. Y. Bao, M. J. Jafari, J. Bergqvist, T. Ederth, M. R. Andersson, and O. Inganäs

Advanced Energy Materials, 2014, 4, 1400643

9. A Renewable Biopolymer Cathode with Multivalent Metal Ions for Enhanced Charge Storage

S. Admassie, A. Elfwing, E. W. H. Jager, Q. Y. Bao, and O. Inganäs Journal of Material Chemistry A, 2014, 2, 1974

10. Solution-Processable Graphene Oxide as an Efficient Hole Injection Layer for High Luminance Organic Light-Emitting Diodes S. W. Shi, V. Sadhu, R. Moubah, G. Schmerber, Q. Y. Bao, and S. Ravi P. Silva Journal of Materials Chemistry C, 2013, 1, 1708

11. Hybrid Intermediate Connector for Tandem OLEDs with the Combination of $\mathrm{MoO}_{3}$ Based Interlayer and P-Type Doping J. P. Yang, Q. Y. Bao, Y. Xiao, Y. H. Deng, Y. Q. Li, S. T. Lee, J. X. Tang Organic Electronics, 2012, 13, 2243

12. Role of Transition Metal Oxides in Charge Recombination Layer Used in Tandem Organic Photovoltaic Cells

J. Li, Q. Y. Bao, H. X. Wei, Z. Q. Xu, J. P. Yang, Y. Q. Li, S. T. Lee, and J. X. Tang Journal of Materials Chemistry, 2012, 22, 6285

13. Mechanism of $\mathrm{Cs}_{2} \mathrm{CO}_{3}$ as an N-Type Dopant in Organic Electron-Transport Film Y. Cai, H. X. Wei, J. Li, Q. Y. Bao, X. Zhao, S. T. Lee, Y. Q. Li, and J. X. Tang 
Applied Physics Letter, 2011, 98, 123303

14. Light Out-Coupling Enhancement of Organic Light-Emitting Devices with Microlens Array

J. P. Yang, Q. Y. Bao, Z. Q. Xu, Y. Q. Li, J. X. Tang, and S. Shen

Applied Physics Letter, 2010, 97, 223303

15. Catalytic Epoxidation of Stilbene with FePt@Cu Nanowires and Molecular Oxygen L. Hu, L. Y. Shi, H. Y. Hong, M. Li, Q. Y. Bao, J. X. Tang, J. F. Ge, J. M. Lu, X. Q. Cao, and H. W. Gu

Chemical Communication, 2010, 42, 8591

16. Book chapter: "Application of Transition Metal Oxides in Tandem Organic Optoelectronics: Energetics and Device Physics" in New Developments in Metal Oxides Research, Eds. I. Nagy and A. Balogh, Nova Science Publishers, New York, USA (2013), ISBN: 978-1-62808-149-7.

Q. Y. Bao, Y. Q. Li and J. X. Tang 


\section{Conferences}

Energetics at molecule-doped polymer/electrode interface for photovoltaic cells

Q. Y. Bao, X. J. Liu, S. Braun, and M. Fahlman

Materials Research Society (MRS), 2015, April 6-10, San Francisco, California, USA (Talk)

Trap-assisted recombination via integer charge transfer states in organic bulk heterojunction photovoltaics

Q. Y. Bao, O. Sandberg, D. Dagnelund, S. Sanden, S. Braun, H. Aarnio, X. J. Liu, W. M.

Chen, R. Österbacka, and M. Fahlman

Materials Research Society (MRS), 2014, November 30-December 5, Boston, Massachusetts, USA (Talk)

Integer charge transfer state as a promising approach for optimizing organic solar cell efficiency

Q. Y. Bao, O. Sandberg, S. Sandén, S. Braun, H. Aarnio, X. J. Liu, R. Österbacka, and M. Fahlman

International Conference for Science and Technology of Synthetic Metals (ICSM), 2014, June 30-July 5, Turku Finland (Talk)

Oxygen- and water-based degradation mechanism in PCBM films

Q. Y. Bao, X. J. Liu, S. Braun, and M. Fahlman

Materials Research Society (MRS), 2013, December 1-6, Boston, Massachusetts, USA (Talk)

Optimizing organic solar cell efficiency using the integer charge transfer model

Q. Y. Bao, X. J. Liu, D. Degnelund, S. Braun, and M. Fahlman

Hybrid and Organic Photovoltaics (HOPV), 2014, May 11-14, Lausanne, Switzerland (Poster)

Electronic structure of solution processed donor-acceptor heterojunctions: the effect of dark state interface dipole and blend de-mixing

Q. Y. Bao, X. J. Liu, S. Braun, S. W. Shi, and M. Fahlman

Materials Research Society (MRS), 2013, December 1-6, Boston, Massachusetts, USA (Poster) 


\section{Acknowledgements}

First of all, I would like to express my sincere thanks to my supervisor, Prof. Mats Fahlman for giving me the precious opportunity to pursue my Ph.D study in the Surface Physics and Chemistry Division. A great deal of time and efforts has been devoted to supervision, help, support and encouragement during my past 4 years. I want to say that I very enjoy the open research atmosphere in your group, and I learned a lot from you, which will be the valuable asset in my future career.

Great gratitude also goes to my co-supervisor, Dr. Xianjie Liu and Dr. Slawomir Braun, who not only helped me with UHV systems, but also shared me with their abundant scientific knowledge.

I would also thank all of the members of the Surface Physics and Chemistry Division, past and present, for assistance in the lab. Special acknowledgments to our administrator Kerstin Vestin for all the help with practical things.

Moreover, I am grateful to all collaborators and co-authors to the papers.

I want as well to thank all my Chinese friends in Linköping, not explicitly mentioned here.

Finally, I would like express my deepest appreciation and thanks to my wife Jing Zhang, my parents, my sister and her family. It is you to always support me all the years. 

Abbreviations
$\mathrm{E}_{\mathrm{F}} \quad$ Fermi level
VL Vacuum level
$\Delta \quad$ Vacuum level potential step
HOMO Highest occupied molecular orbital
LUMO Lowest unoccupied molecular orbital
IP Ionization potential
EA Electron affinity
ICT $+\quad$ Positive integer charge transfer state
ICT- $\quad$ Negative integer charge transfer state
UHV Ultra high vacuum
PES Photoelectron spectroscopy
XPS X-ray photoelectron spectroscopy
UPS Ultraviolet photoelectron spectroscopy
NEXAFS Near edge X-ray absorption fine structure
OSC Organic semiconductor
OPV Organic photovoltaic
BHJ Bulk heterojunction 


\section{Contents}

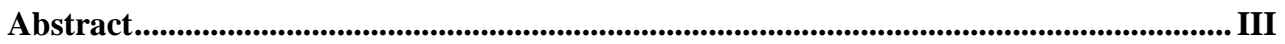

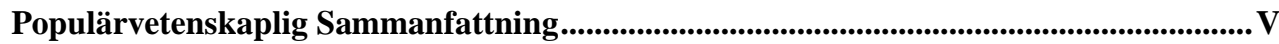

List of Publications Included in this Thesis.......................................................................... VII

List of Publications not Included in this Thesis ............................................................... VIII

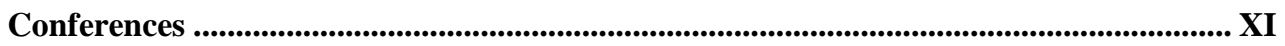

Acknowledgements ................................................................................................... XIII

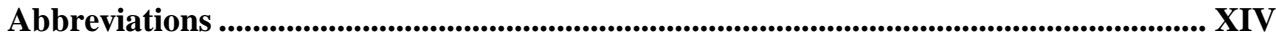

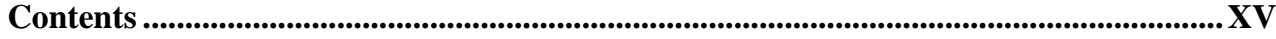

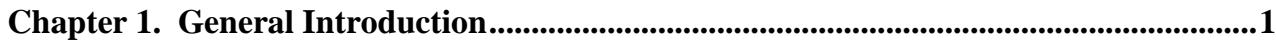

Chapter 2. Basic Properties of Conjugated Polymer........................................................5

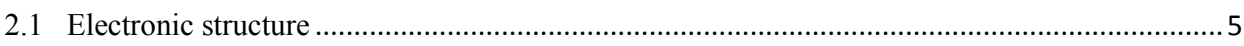

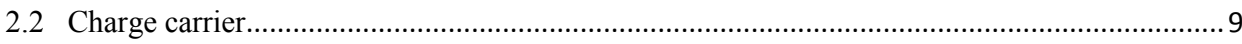

Chapter 3. Interface Energetics in Organic Electronics ...................................................13

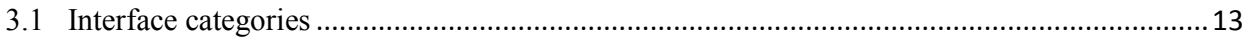

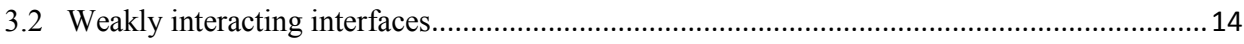

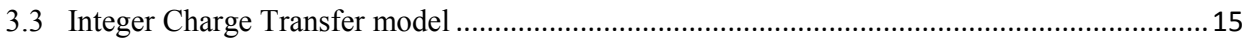

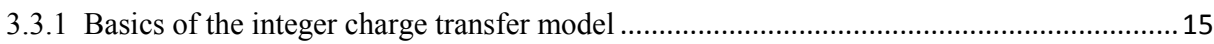

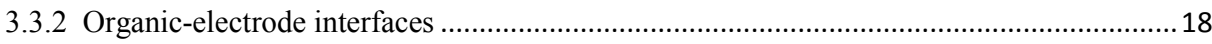

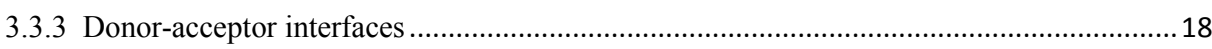

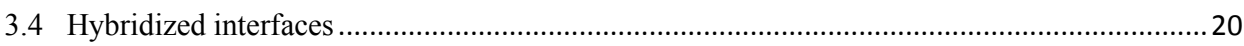

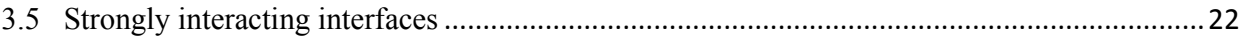

Chapter 4. Photoelectron Spectroscopy and X-ray Absorption Spectroscopy ................25

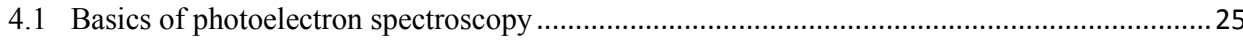

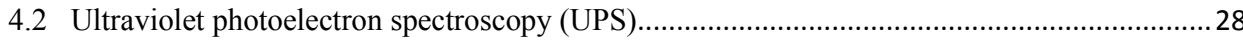

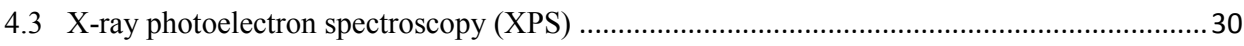

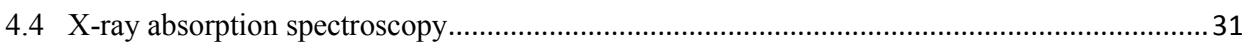

Chapter 5. Operation Principles of Organic Solar Cell ....................................................35

Chapter 6. Summary of Papers Included in the Thesis.................................................39

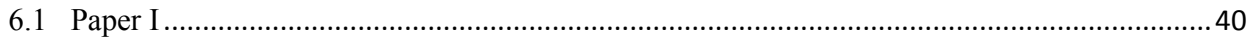

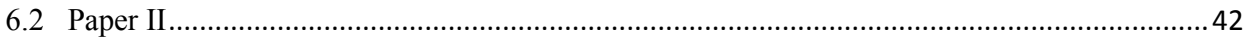

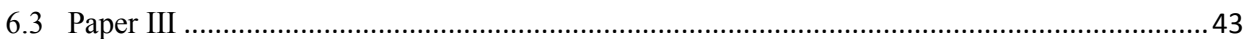




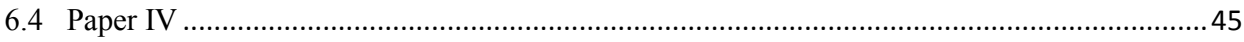

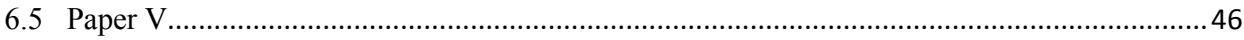

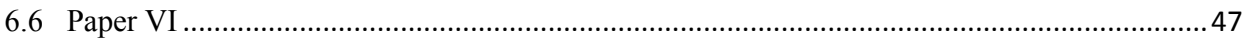

Chapter 7. Future Outlook.......................................................................................................49

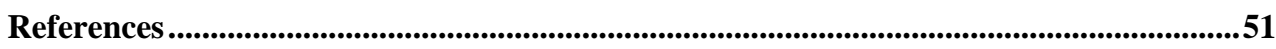

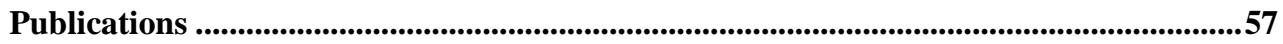




\section{Chapter 1. General Introduction}

The field of organic electronics is rapidly growing based on $\pi$-conjugated organic semiconductors (OSCs), i.e. small molecules and polymers, with applications in e.g. thin-film transistors (OTFTs $)^{1}$, light emitting diodes $(\mathrm{OLEDs})^{2}$, photovoltaic cells $(\mathrm{OPVs})^{3}$, photodetectors ${ }^{4}$, memory cells ${ }^{5}$, laser $^{6}$ and spintronics ${ }^{7}$. The interest is mainly a function of a wide variety of potential advantages of OSCs that are hard to achieve in inorganic components, such as low temperature processing, light weight, low manufacturing cost, high throughput, mechanical flexibility, tunable optical and electronic properties through synthesis. To date, OLEDs have found their way into commercial products featuring remarkable color resolution displays in, e.g. cell phones and televisions, whereas OTFTs and OPVs are still waiting for a commercial breakthrough. Especially, the development of OPVs as a promising renewable-energy source has intensified and energy conversion efficiencies of $\sim 11 \%$ have been demonstrated ${ }^{8,9}$. All such OSC-based devices mentioned above are deposited as thin film architectures and thus contain several interfaces, metal-organic and/or organic-organic, that significantly determine performance and lifetime. Many key electronic processes as charge injection/extraction, charge recombination and exciton dissociation occur at interfaces ${ }^{10-12}$. In fact, even charge transport can be seen as a special injection behavior across organic-organic junction since the charges are localized on molecules ${ }^{13}$. Therefore, one of the crucial issues for organic electronic technologies is to understand and predict interface energetics and its effect on device operational efficiency ${ }^{14-16}$.

Many studies find that the interface phenomena of weakly interacting interface follow the socalled integer charger transfer (ICT) model where heterojunctions are characterized by weak van der Waals intermolecular bonding ${ }^{17-19}$. The cases for the type of interfaces exist in metalorganic and organic-organic junctions prepared by solution process of polymer under ambient conditions and by thermal evaporation of small molecule under vacuum conditions. The relation between the original Fermi level of a surface and the pinning energies of OSCs are divided into three regimes considering oxidization/reduction of segments (molecules) adjacent to the interface: (i) Fermi level is pinned at negative ICT density of states with an up-shift potential step, (ii) Vacuum levels align, (iii) Fermi level is pinned at positive ICT density of states with a down-shift potential step ${ }^{19,20}$. The size of potential step scales with the difference between equilibrium ionization potential (iii)/electron affinity (i) of OSCs at 
interface $\left(\mathrm{E}_{\mathrm{ICT}+/-}\right)$ and the work function of the underlying substrate, which is originated from spontaneous charge transfer across interface via tunneling.

Bulk heterojunction OPV device is a main topic of the thesis, excitons created upon photon absorption in the active layer diffuse into the donor-acceptor interface region where they are transformed into charge transfer excitons, and subsequently dissociated into free charges that will finally be transported into electrodes. To put it simply, the lowest unoccupied molecular orbital (LUMO) energy level offset at donor-acceptor interface should be large enough to overcome the exciton binding energy to assist the transformation, but if the offset is too large, loss of open circuit voltage will occur ${ }^{21}$. Furthermore, a potential step at donor-acceptor interface can enhance the percentage of charge transfer excitons transformed into free chargers that contribute to short circuit current, while simultaneously decrease open circuit voltage $\mathrm{e}^{22,23}$. The energetics at active layer-electrode interface also are of tremendous importance because barriers toward the charge extraction can diminish open circuit voltage, and surface states at the electrode can lead to reduce overall efficiency due to trap-assisted recombination ${ }^{24}$. It is clear that the energetics at both donor-acceptor and electrode interfaces in OPVs should be optimized so as to minimize device efficiency loss.

Photoelectron spectroscopy including ultraviolet and X-ray photoelectron spectroscopy is a successful surface science technique to map out energetics at interface and surface chemical states with advantages of being relatively non-destructive to OSCs and extremely surface sensitive ${ }^{25,26}$. The technique enables direct probing of the work function, the vertical ionization potential, the occupied density of states, the simplified hole injection barrier and the vacuum level shift upon forming an interface, as well as the pinning energies in combination with the ICT model that governs the weakly interacting interface energetics. For such measurements, ultraviolet light is typically used, whereas x-ray is used for tracking the possible chemical interaction at interface and the change of chemical states at the surface. Near edge X-ray absorption fine structure spectroscopy yields information about the unoccupied electronic structure and the molecular orientation that may significantly affect the interface energetics ${ }^{27}$.

In this thesis, six papers regarding the issues mentioned above are included. Paper I proposes new design rules for donor-acceptor interfaces for optimizing open circuit voltage and overall performance of OPVs, in fact enabling not just efficient screening of OSC donor and acceptor materials but also in silico design thereof. Paper II reveals the completely different 
degradation mechanisms of interface energetics of PCBM-electrode interface caused by oxygen and water. Paper III proposes a general model for energy level bending in absence of significant doping of conjugated polymer films, showing experimental results that overturn some of the recent models. Papers IV and $\mathbf{V}$ are devoted to developing a universal model for handling interface energetics that simultaneously treats doped conjugated polymers and conjugated electrolyte/electrode interfaces, which are two established methods for improving charge injection/extraction efficiency. Paper VI presents the effect of the environment, e.g. UV-light soaking under different conditions, on surface electronic structures of $\mathrm{ZnO}$ nanoparticle interlayer films and the OPV performance.

Following the general introduction of Chapter $\mathbf{1}$ in this thesis, a short description of basic properties of conjugated polymer is given in Chapter 2. Chapter 3 in detail provides reader with description of various interface energetics in organic electronics depending on the strength of interface interaction from weakly interacting, hybridization to strongly interacting interfaces. The ICT model applied in weakly interacting interfaces existing in OPVs is discussed. In Chapter 4, the experimental techniques of photoelectron spectroscopy and Xray absorption are presented. The operation principles of OPVs are included in Chapter 5. Chapter 6 summarizes the papers included in this thesis, and the further outlook is given in Chapter 7. 


\section{Chapter 2. Basic Properties of Conjugated Polymer}

\subsection{Electronic structure}

Conventional polymers, plastics, were for a long time after their discovery viewed as insulators only. The concept of electrically conducting polymer can date back to the molecular crystal research in the $1960 \mathrm{~s}$, and later, in 1970 s the science of $\pi$-conjugated polymer was established when it was found through successful synthesis and use of doping that polyacetylene can have metallic-like electrical conductivity ${ }^{28,29}$. Since then, intense attention has been paid to this type of organic materials, leading to their significant application in devices, such as field-effect transistors and integrated circuits ${ }^{1,30}$, light-emitting diodes $^{2}$, photovoltaic cells ${ }^{3}$, detectors ${ }^{4}$, memories $^{5}$, solid-state lasers ${ }^{6}$ and spintronics ${ }^{7}$ with various potential advantages compared to the inorganic counterparts such as high throughput, cheap manufacturing cost, light weight, and mechanical flexibility.

(a)
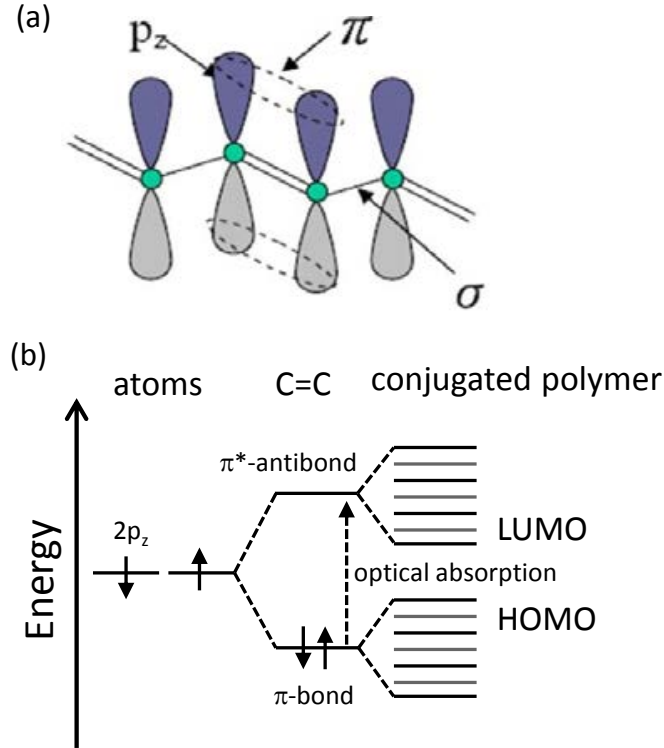

Fig. 2.1 (a) $\sigma$ bond and $\pi$ bond diagram in a conjugated polymer. The overlap of the adjacent $2 p_{z}$ orbitals results in the formation of the delocalized $\pi$ bond. (b) Schematic diagram of HOMO level and LUMO level derived from occupied $\pi$-bonding orbitals and unoccupied $\pi^{*}$-antibonding orbitals. Adapted from Reference ${ }^{31}$ 
Conjugated polymers consist mainly of a continuous network, often long-chain, of organic molecules with a series of alternating double and single bonds between the adjacent carbon atoms, which in fact is what enables the semiconducting or conducting properties (Fig. 2.1a). Because the electronic structure configuration of carbon is $1 \mathrm{~s}^{2} 2 \mathrm{~s}^{2} 2 \mathrm{p}^{2}$ and the $1 \mathrm{~s}$ core level does not contribute to the chemical bonding, the electron conjugation results in the so-called $\mathrm{sp}^{2}$ hybridized state yielding three covalent $\sigma$ bonds $\left(2 \mathrm{~s}, 2 \mathrm{p}_{\mathrm{x}}\right.$ and $\left.2 \mathrm{p}_{\mathrm{y}}\right)$ with neighboring carbon and hydrogen atoms within one co-plane. The remaining $2 p_{z}$ orbital is free to overlap with the corresponding one on a neighboring atom resulting in the formation of another chemical bond known as the $\pi$ bond. The $\pi$-bonds induce states that can be delocalized along the polymer chain. The highest occupied molecular orbital (HOMO) similar to the valence band in inorganic materials and the lowest unoccupied orbital (LUMO) analogous to the conduction band are derived from the occupied $\pi$-bonding orbitals and the unoccupied $\pi^{*}$ antibonding orbitals, respectively ${ }^{32,33}$. The frontier electronic bands are separated by the $\pi$ bond-antibonding gap, see Fig. 2.1b, which accounts for the optical absorption of low energy excitation and semiconductor behavior.

(a)

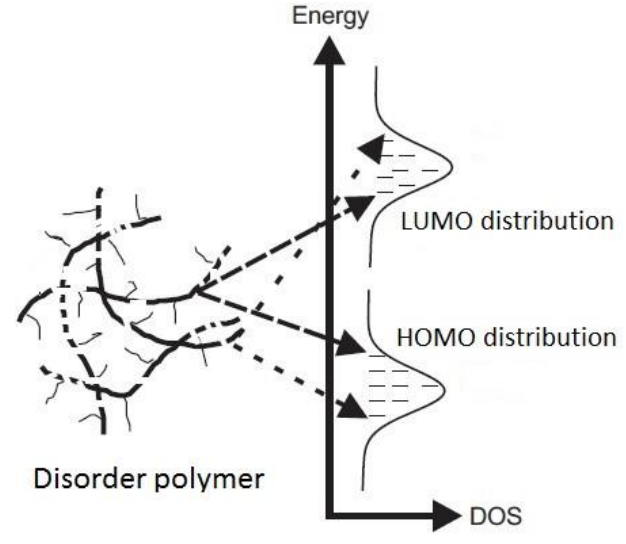

(b)

Vacuum level

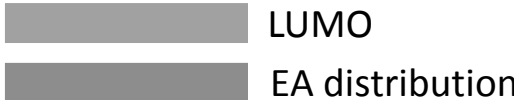

Conjugated polymer film

Fig. 2.2 (a) Representation of the energy Gaussian distribution of the HOMO and LUMO levels. Adapted from Reference ${ }^{34}$ (b) IP and EA distribution in related to the vacuum level depending on the intermolecular order and the nature of surrounding chains in conjugated polymer film. Energy differences between $\mathrm{HOMO} / \mathrm{LUMO}$ and IP/EA originate from the relaxation process.

Energy bands in a solid originate from orbital overlap amongst its large number of particles and a well-defined crystal lattice structure. Polymer chains aggregate in films via weak van der Waals force which holds them together, making them "soft" materials. In practice, the 
real polymer films are seldom single crystal films, and are instead amorphous ${ }^{35}$, at best polycrystalline $\mathrm{e}^{36}$ or the mixture of well ordered (polycrystalline) regions and disordered (amorphous) regions ${ }^{37}$, which means that the concept of energy bands does not generally hold. The electronic structures of polymer films instead typically are defined by localized states. Due to the variations in the conjugation lengths and in the interaction energetics of conjugated polymers, there is a distribution of the density of states of HOMO and LUMO, often modeled as following a Gaussian shape (Fig. 2.2a). The ionization potential (IP) is defined as minimum amount of energy required to remove an electron from a neutral polymer chain to form a fully relaxed positive ion, and the electron affinity (EA) is maximum amount of energy released when an electron is added to a neutral chain form a fully relaxed negative $\operatorname{ion}^{38}$.

Since the IP and EA derived from these molecular orbitals also largely depend on the intermolecular order and the nature of surrounding chains, in conjugated polymer films, a broad distribution of IP/EA occurs for each orbital ${ }^{39}$ (Fig. 2.2b). The energy gap is then defined by the upper edge of the IP energy distribution and the lower edge of the EA energy distribution, those edges becoming the film IP and EA respectively. There are consequently then per definition no gap states in absence of doping or synthetic defects, which is fundamentally different from a single crystal. It is noted that IP (EA) is equal to HOMO (LUMO) only if there is no electronic and no nuclear relaxation process withdrawing (receiving) an electron ${ }^{40}$. The frontier part of the IP and EA is typically modeled as being either Gaussian or exponential, and the most easily oxidized/reduced states in the IP/EA distribution are typically then referred to as tail states. In fact, the position in the IP/EA that separates the "tail" states from the "proper" states are not easily defined except for a $\sim$ perfect single-crystal organic semiconductor film. 


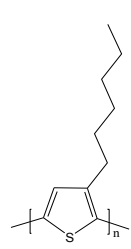

rr-P3HT

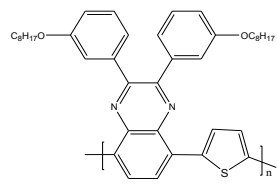

TQ1
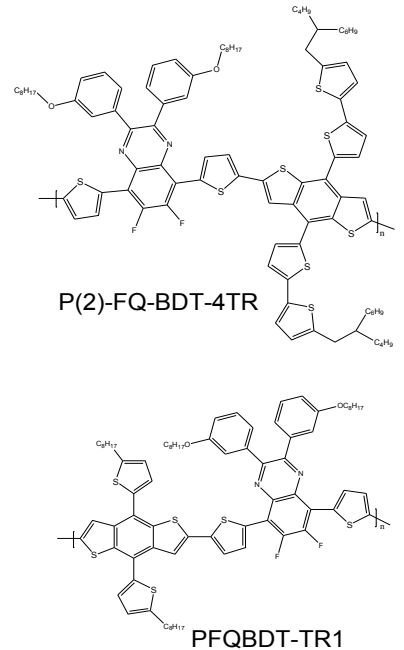

PFQBDT-TR1

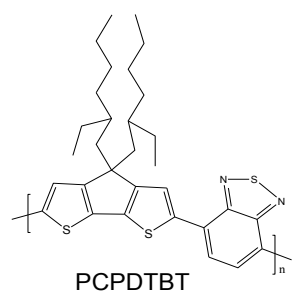

PCPDTBT
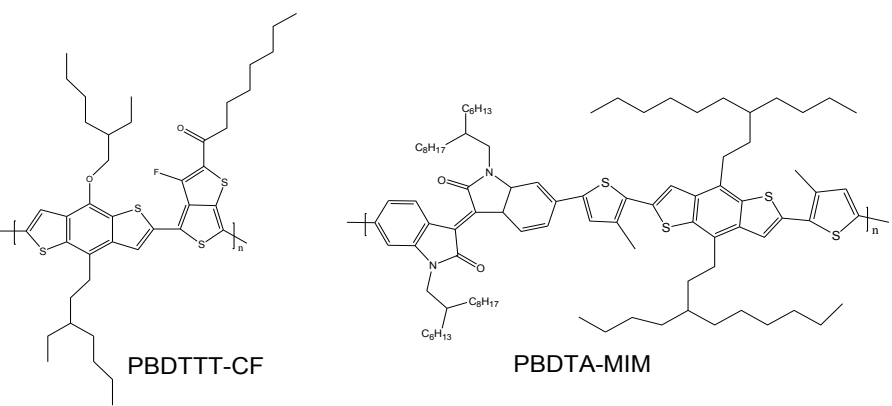

Fig. 2.3 Chemical structures of partial conjugated polymers used in the thesis.

Much attention has been invested into the synthesis of various conjugated polymers with different electronic structures tailored for their applications in recent years ${ }^{41-44}$. Fig. 2.3 shows chemical structures of some conjugated polymers used in this thesis. Fig. 2.4 further depicts the two examples with the frontier occupied electronic features derived from UPS spectra, which can be applied to roughly confirm that the amorphous/disordered nature of the polymer film produces a broad tail states distribution, while a sharp structure corresponds to the well-ordered polymer film. 


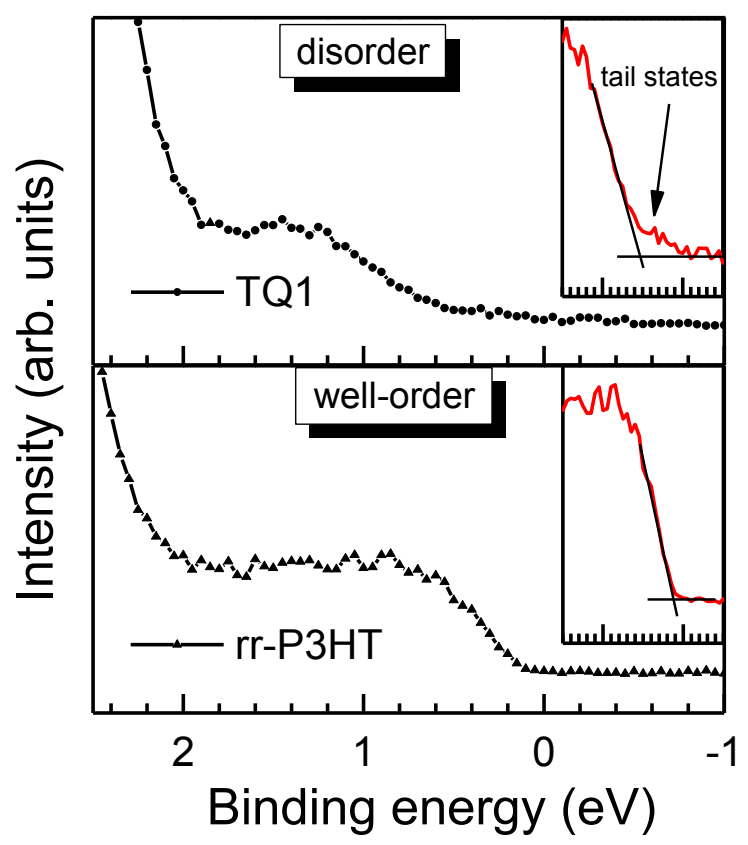

Fig. 2.4 Examples of disorder TQ1 and well-order rr-P3HT film with the frontier occupied electronic feature derived from UPS spectra.

\subsection{Charge carrier}

Unlike inorganic semiconductor, conjugated polymers are soft materials with low charge carrier mobility and low dielectric constant: adding (withdrawing) an electron to (from) antibonding LUMO (bonding HOMO), the chain shape and the lattice are deformed to compensate with significant change in the energy of the now-populated LUMO and populated HOMO. Therefore, when approaching the energy level alignment for charge transport and charge injection/extraction barrier, both of previous LUMO and HOMO of the neutral system are not relevant, and the energy of the singly occupied molecular orbital of the ionization has to be considered. Depending on backbone of polymer chain, conjugated polymers have either degenerate or non-degenerate ground state geometry corresponding to the different nature of charge carriers, e.g. soliton and polaron respectively, which enable electronic conduction ${ }^{45,46}$.

The energy of the degenerate ground state is equal for the two configurations due to the equivalence in order in which the single and double carbon bond arrange alternately, like 
polyacetylene. Soliton gives a localized state in the electronic structure, which locates inside the HOMO-LUMO gap. The neutral soliton has a spin $1 / 2$. However, with addition of extra electron, negatively charged soliton created is spin-less. Extraction of electron leads to the formation of another spin-less positively charged soliton. Generally, the process is achieved through doping when charge transfer occurs between the polymer chain and the dopant ${ }^{47}$.

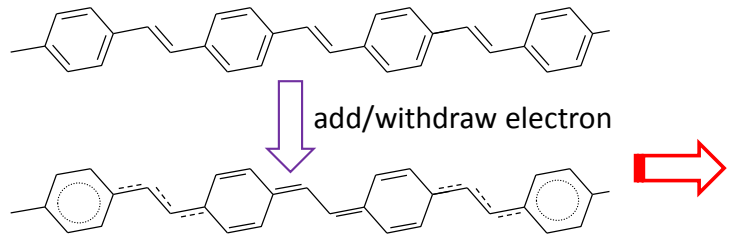

Charge and geometrical distortion!

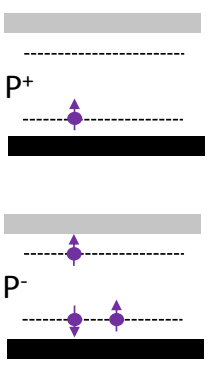

LUMO

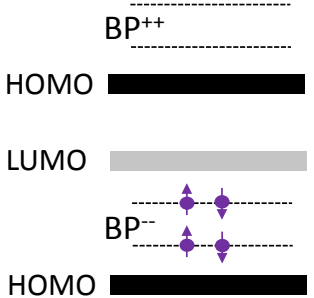

Fig. 2.5 Polaron and bipolaron formation when adding/withdrawing electron in non-degenerate ground state geometry conjugated polymer. Adapted from Reference ${ }^{20}$

In principle, the vast majority of conjugated polymers are of non-degenerate ground state type. The charge-carrying states acting as a quasi-particle are called polarons featuring local deformation of the bond conjugation caused by interaction between excess charges and the quinoid segments, which differ significantly in energy from the HOMO or LUMO edges of the neutral polymer ${ }^{48}$. Such polaronic states also reside in the forbidden HOMO-LUMO gap resulting in new photon absorption transitions. Because of a strong electron-lattice coupling, charge over a part of polymer chain is localized and the significant distortion of the corresponding geometrical structure occurs. Fig. 2.5 illustrates the energy levels of polaronic states in conjugated polymer. $\mathrm{P}^{+}$is the positive charge state and $\mathrm{P}^{-}$is the negative charge state. When two polarons are close enough to interact, e.g. in case of high doping level, they form bipolarons, $\mathrm{BP}^{++}$and $\mathrm{BP}^{--}$that carry double charges ${ }^{49,50}$. As depicted in Fig. $2.5 \mathrm{P}^{+}$state above HOMO level is half-filled and the state below LUMO level is empty. For $\mathrm{P}^{-}$state, there are two charges above HOMO level (filled) and only one charge below the LUMO level (halffilled). In other words, they have density of states at the Fermi level. In case of bipolaron states, Fermi level is situated half-way between HOMO level and the lowest lying bipolaron state for $\mathrm{BP}^{++}$, and half-way between LUMO level and the highest lying bipolaron state for $\mathrm{BP}^{--}$, meaning that there is no density of states at the Fermi level ${ }^{51}$. The classic evidence is 
derived from the UPS measurement on rubidium-doped poly(p-phenylenevinylene) system reported by Salaneck's group in $1995^{52}$. Considering the polaron state within the gap, the polaron absorption also can be used to identify the presence of polarons in transient absorption $^{53}$ and photo-induced absorption measurement ${ }^{54}$. 


\section{Chapter 3. Interface Energetics in Organic Electronics}

\subsection{Interface categories}

Organic electronic devices are made by deposition of successive layers, e.g. organic semiconductors, metals, oxides or insulators combining in the formation of several interfaces, and many key electronic processes, e.g. charge injection/extraction, charge recombination and exciton dissociation, occur at interfaces, which play a critical role in device performance and function ${ }^{10,11,14-16,19,20,55}$. It is thus of great importance to understand the energetics at both organic-metal (electrode) and organic-organic interfaces as well as their influence on the operational efficiency. When $\pi$-conjugated polymers are adsorbed on the surface of another material, the interface energetics may be controlled by several possible effects: interaction between electron density of polymer and image charge on metal, partial charge transfer though covalent polymer-metal bonds, integer charge transfer via tunneling across interface and surface rearrangement as well as absorption-induced orientation, etc $^{14}$. Depending on the strength of the interface interaction, the types of conjugated polymer (molecule) interface can be categorized from strong (chemisorption with covalent bonding) to weak scenario (physisorption with no charge transfer) as shown in Fig. 3.1.

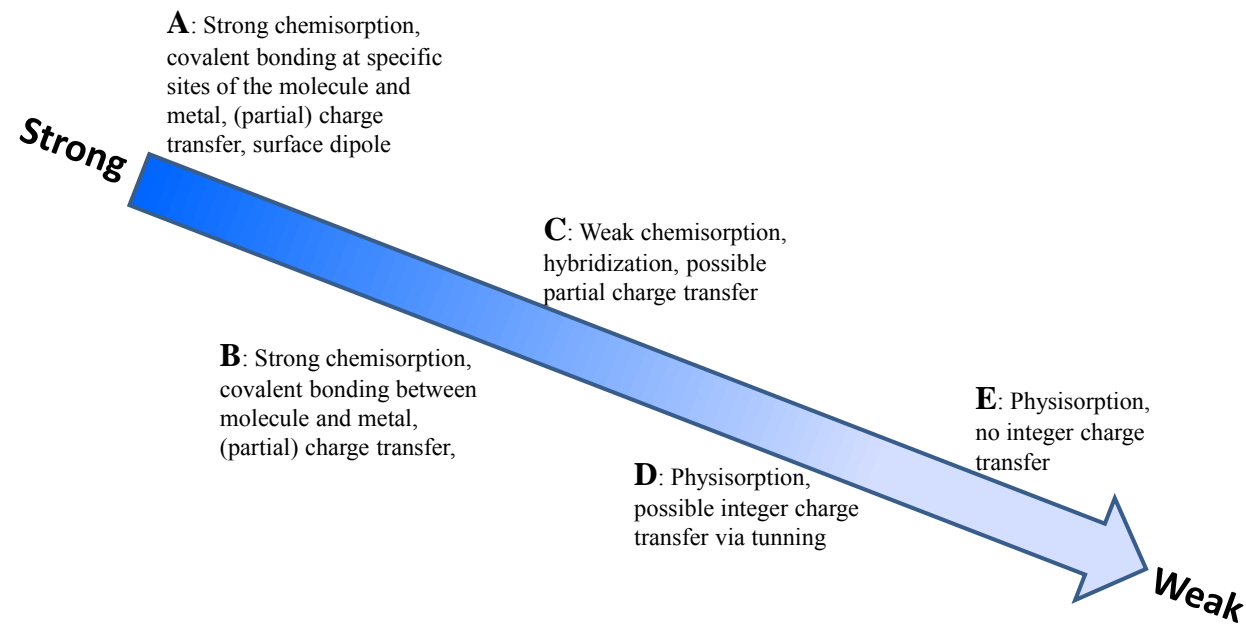

Fig. 3.1 Category of $\pi$-conjugated polymer interface. Interface examples: A for OSCs with intrinsic dipole and anchoring groups on clean metal surfaces ${ }^{56}$; B for OSCs on reactive clean metal surfaces ${ }^{57}$; $\mathrm{C}$ for OSCs on non-reactive clean metal surfaces ${ }^{58}$; D for OSCs on organic or passivated metal surfaces $^{17}$; E for noble gas atoms or saturated hydrocarbons on clean metal surfaces ${ }^{59}$. 
Currently there is no universal model for describing all types of interfaces above. In this thesis most of the work is focused on the weakly interacting interface, which widely occurs in organic-electrode and organic-organic contacts of solution processed polymer-based electronic devices, and the corresponding integer charge transfer model ${ }^{60,61}$. For comparison, both hybridized interfaces and strongly interacting interfaces involving conjugated OSCs are also introduced.

\subsection{Weakly interacting interfaces}

Weakly interacting interfaces are characterized by a negligible overlap of $\pi$-electronic orbitals with the substrate wave functions. Such interfaces are typically created by spincoated conjugated polymer on a passivated surface with oxides or residual hydrocarbon contaminants under ambient atmosphere or by thermally evaporating small molecule under high vacuum conditions, preventing the electronic coupling and consequently blocking the formation of the partial electron transfer induced dipole at organic-metal and organic-organic interface $^{17,18}$. At this type of interface, electron transfer occurs through tunneling as long as the native oxides/hydrocarbons are thin enough, which implies the transfer of an integer amount of charge, one electron at a time, into well-defined charged states on the conjugated polymer $^{62}$.

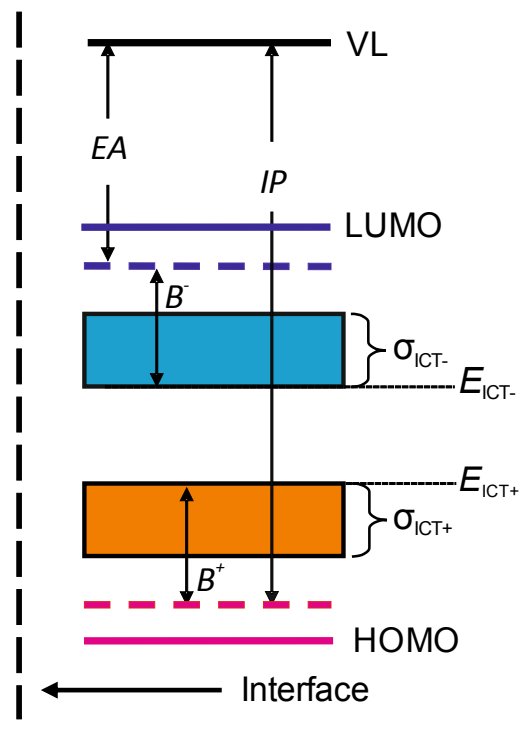

Fig. 3.2 Energetics at the type of weakly interacting interface. EA, IP, LUMO and HOMO simply represent their distribution edge in relation to the VL. $\sigma_{\mathrm{ICT}+/-}$ is the ICT state distribution. 
The so-called pinning energies, $\mathrm{E}_{\mathrm{ICT}+}\left(\mathrm{E}_{\mathrm{ICT}-}\right)$, relate to the smallest energy required to take away one electron (the largest energy gained from adding one electron) from (to) the polymer chain producing a fully relaxed state, i.e. the edge of the respective ICT energy distribution, see Fig. 3.2. Considering adding/withdrawing electron leads to localized polaron or bipolaron states in $\pi$-conjugated polymer (see section 2.2), the ICT states at the interface then appear as new features in the energy level gap and separated from the HOMO/LUMO level of neutral polymer, and finally determine the energy level alignment of the weakly interacting interface. Fig. 3.2 shows the interface energetics. It is stressed that $\mathrm{E}_{\mathrm{ICT}+/-}$ are similar in nature to but differ from IP/EA due to Coulomb interaction with the opposite charge across the interface where $\mathrm{E}_{\mathrm{ICT}+}=\mathrm{IP}-\mathrm{B}^{+}, \mathrm{E}_{\mathrm{ICT}-}=\mathrm{EA}+\mathrm{B}^{-}$, and $\mathrm{B}^{+/-}$value donates the Coulomb energy associated with charging a polymer chain at the interface with one charge ${ }^{63}$. The distribution of ICT $+/-$ states depends on inter- and intra-polymer $\operatorname{order}^{20}$. Unless a crystal film, the interface polarons will be localized on one or more polymer chain, but will not be delocalized over the film in a band-like picture. It is stressed that the ICT states are not pre-existing polarons, nor are they photogenerated, they are created upon interface formation as the result of equilibration of the Fermi level ${ }^{13,17,19,61}$.

\subsection{Integer Charge Transfer model}

\subsubsection{Basics of the integer charge transfer model}

Based on the nature of the weakly interacting interface mentioned above, the Integer Charge Transfer (ICT) model ${ }^{13,17,19,20,61,62,64,65}$ can successfully describe and predict the equilibrium energy level alignment behavior for such interfaces. A "Mark of Zorro"-shaped abrupt transitions between a Schottky-Mott regime and Fermi-level pinning regimes are observed upon variation of work function of underlying substrate to create interfaces spanning low to high work function (Fig. 3.3). The Schottky-Mott regime is defined by vacuum level alignment while Fermi level pinning regimes feature the formation of a potential step that scales with difference between the equilibrium IP or EA of the conjugated polymer at the interface $\left(\mathrm{E}_{\mathrm{ICT}+/-}\right)$ and the work function of the substrate. The origin of the potential step is explained by spontaneous charge transfer across the interface via tunneling (integer charge transfer) when the substrate work function is greater (lower) than the energy required to oxidize (gained from reducing) a polymer segment at the interfaces. The most easily oxidized/reduced of $\pi$-delocalized backbone adjacent to the interface hence will be "used up" until enough charge has been transferred across the interface to create a potential step that 
equilibrates the Fermi level. The energy where the Fermi level is subsequently pinned is referred to as $\mathrm{E}_{\mathrm{ICT}+\text {,- }}$ (same concept as the smallest energy required to take away one electron or the largest energy gained from adding one electron at interface producing a fully relaxed state in session 3.2) depending on if it is positive or negative polarons that are being created. In detail three distinct energy level alignment regimes as per the ICT model are described by Fig. 3.3:

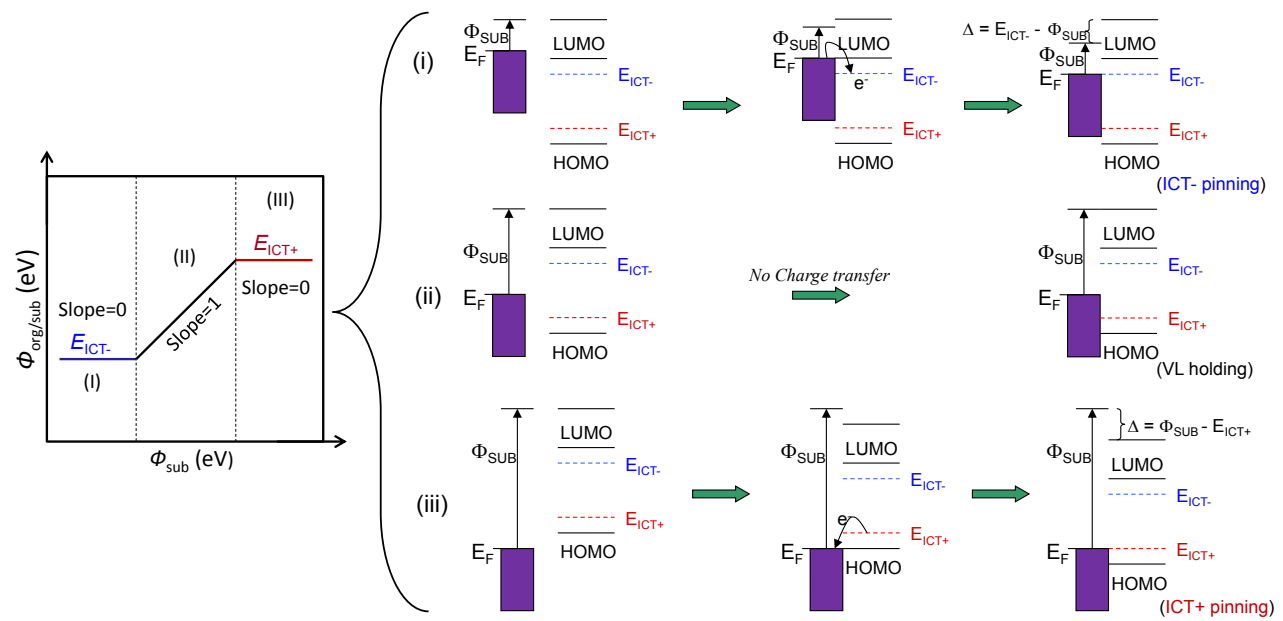

Fig. 3.3 A schematic illustration of the three energy level alignment regimes in the ICT model. Adapted from Reference ${ }^{19}$

(i) $\Phi_{\text {sub }}<$ E $_{\text {ICT- }}$ - Fermi level pinning to a negative integer charge transfer state via integer electron spontaneously flowing from substrate to polymer, resulting in a substrateindependent work function, slope $=0$;

(ii) $\mathrm{E}_{\mathrm{ICT}-}<\Phi_{\text {sub }}<\mathrm{E}_{\mathrm{ICT}+}-$ Vacuum level alignment, giving a substrate-dependent work function without charge transfer, slope $=1$;

(iii) $\Phi_{\text {sub }}>E_{\mathrm{ICT}+}-$ Fermi level pinning to a positive integer charge transfer state via integer spontaneously flowing from polymer to substrate, resulting again in a substrate-independent work function slope $=0$. 

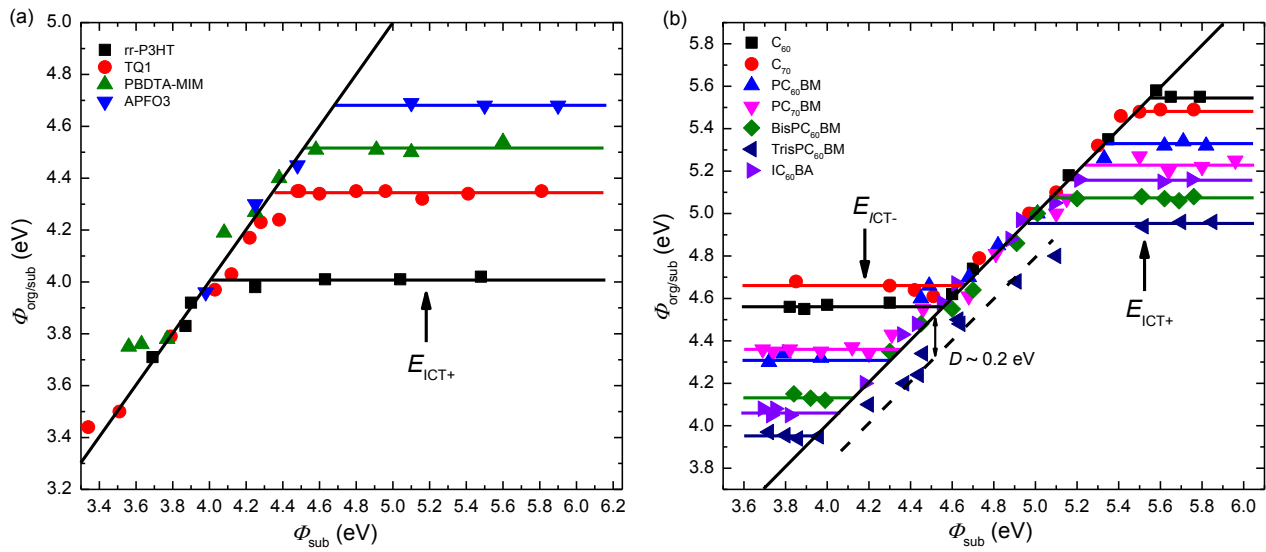

Fig. 3.4 ICT behaviors of frequent (a) donor polymers and (b) acceptor fullerenes. D is the energy downshift away from the ideal ICT behavior attributed to the preferential ordering of $\operatorname{tris} \mathrm{PC}_{60} \mathrm{BM}$ adducts. Adapted from Reference ${ }^{23}$

Fig. 3.4 shows the universal ICT energetic behavior and $\mathrm{E}_{\mathrm{ICT}+/-}$ values of donor polymers (the chemical structures previously depicted in Fig. 2.3 of section 2.1) and acceptor fullerenes

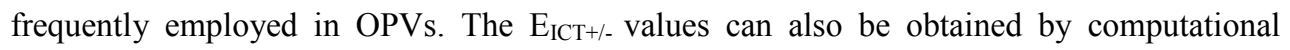
methods ${ }^{16,66,67}$ where the density functional theory (DFT) approached by G. Brocks et $\mathrm{al}^{63,68,69}$ was the first to demonstrate calculated values in excellent agreement with experimental results.
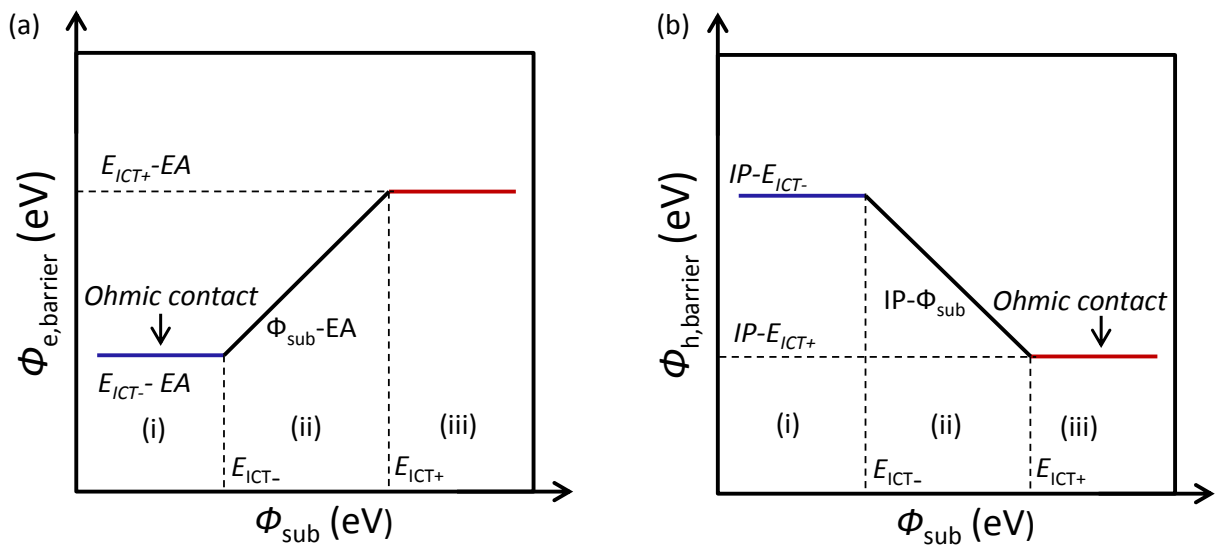

Fig. 3.5 (a) Electron injection barrier and (b) hole injection barrier as a function of the underlying substrate work function in three regimes. 


\subsubsection{Organic-electrode interfaces}

The ICT model provides a simple and effective path to tailor charge injection/extraction barrier at electrode interfaces. Energetics at electrode contacts are important as barriers towards charge injection increase turn-on voltage and decrease the hole-electron recombination possibility in the case of OLEDs. In the case of OPVs, barriers for charge extraction diminishes open circuit voltage $\left(\mathrm{V}_{\mathrm{oc}}\right)$ due to the built-in potential reduction, leading to an increase in carrier recombination and thus a decrease in the short circuit current (Jsc) as well as the overall power conversion efficiency (PCE). As per the ICT model, the $\mathrm{E}_{\mathrm{ICT}+/-}$ corresponds to the smallest charge injection barrier in formation of ohmic contact with adjacent OSC in which the anode work function should be equal or greater than the $\mathrm{E}_{\mathrm{ICT}+}$ and the cathode work function equal or smaller than $\mathrm{E}_{\text {ICT. }}$. In their transition region (ii), the value of barrier varies as the electrode work function, see Fig. 3.5.

\subsubsection{Donor-acceptor interfaces}

Interface energetics at organic-organic heterojunction can be easily mapped in the ICT model, which widely exists in OPVs serving as donor-acceptor interface. Fig. 3.6 shows the energy level alignment process at donor-acceptor interface under the electrode pinned conditions. (a)

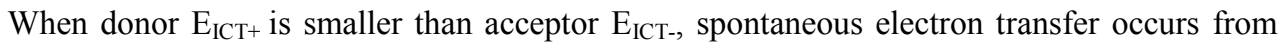
donor to acceptor until the donor ICT + pinned to acceptor ICT- in formation with a negative dipole pointing into the acceptor sider. (b) When donor $\mathrm{E}_{\mathrm{ICT}+}$ is larger than acceptor $\mathrm{E}_{\mathrm{ICT}-\text {, no }}$ charge transfer across the interface and the vacuum level holds. 


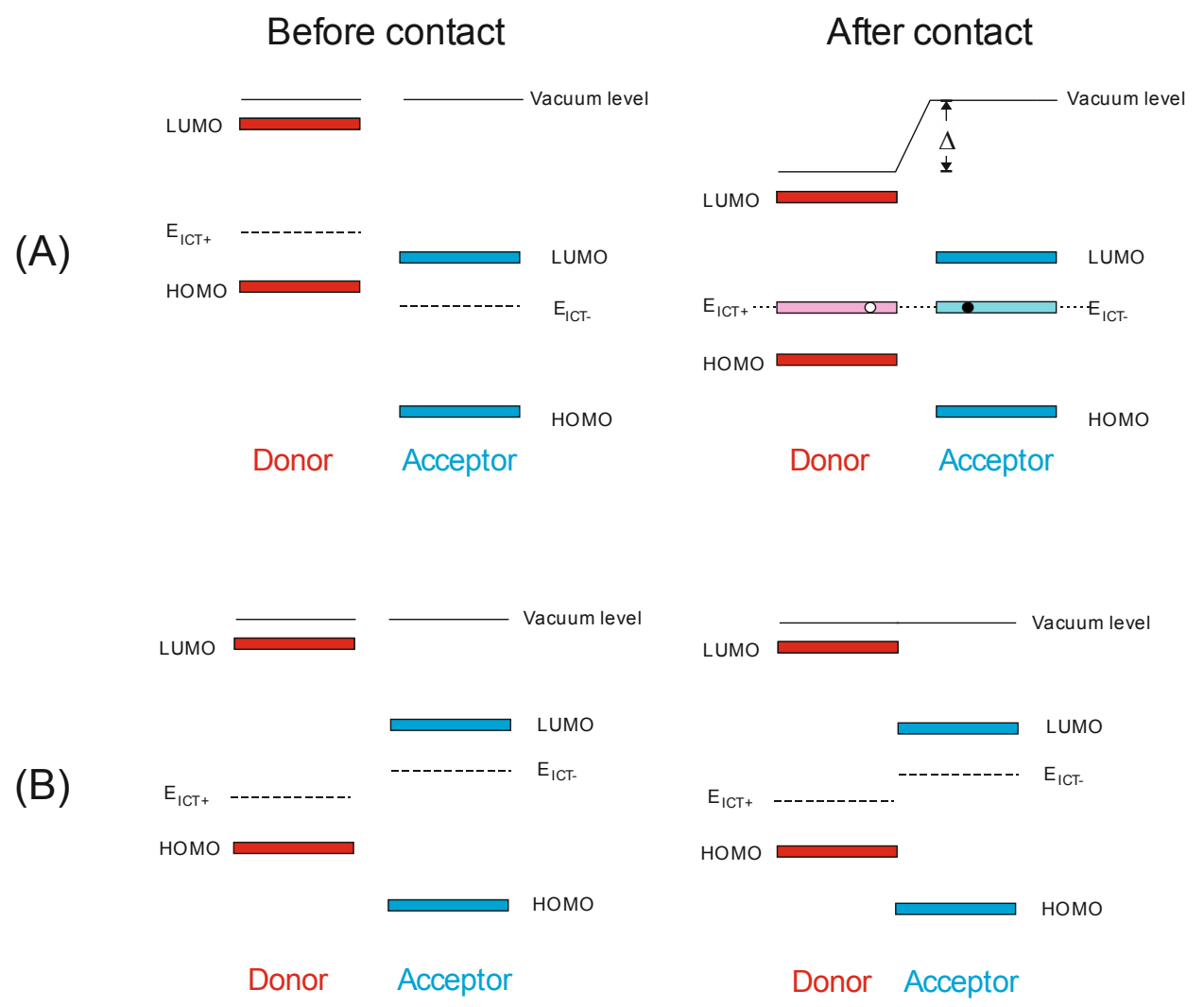

Fig. 3.6 Energy level alignment diagrams for donor-accepter before and after contact when (a) $E_{I C T+}$, donor $<\mathrm{E}_{\mathrm{ICT}-\text {, acceptor, }}$ (b) $\mathrm{E}_{\mathrm{ICT}+\text {, donor }}>\mathrm{E}_{\mathrm{ICT} \text {, acceptor. }}$.

The potential step generated by the equilibration of the ICT states at the interface modifies the energy offset between bulk donor IP and acceptor EA, which is strongly linked to the $\mathrm{V}_{\mathrm{oc}}$ of OPV. The ICT states in dark have profound effect on the $\mathrm{V}_{\mathrm{oc}}$ via trap-assisted recombination in the case (a) of interface ${ }^{23}$. On the other hand, the ICT state populating the most easily oxidized donor chain and the most easily reduced acceptor at interface leads to the most tightly bound sites where charge transfer electron-hole pair could be created at interface having been occupied in the ground state. It means that the tightly bound sites could not participate into exciton separation process under the photon absorption, thus enhancing dissociation of excitons into free charge carriers as confirmed by photoinduced absorption spectroscopy where interface dipole makes exciton dissociation much more efficient resulting in higher charge concentration ${ }^{22,70}$. Based on the energetics at this type of interface, new 
design rules for donor-acceptor interface for optimizing open circuit voltage and overall performance of OPVs were proposed ${ }^{23}$.

\subsection{Hybridized interfaces}

Induced Density of Interfacial States (IDIS) model: Here, the interface features hybridization of the electronic states between $\pi$-conjugated OSC and the underlying substrate surface, though no strong covalent bond is formed. In other words, the chemical interaction at interface is moderate but non-negligible, leading to hybridization of the HOMO and LUMO. Such interfaces are typically created by vapor deposition of organic molecules onto clean nonreactive surfaces such as $\mathrm{Au}$ and $\mathrm{Pt}$ in $\mathrm{UHV}$, and the resulting interaction is slightly stronger than the weakly interacting interfaces covered by the ICT model mentioned in section 3.3. The IDIS model ${ }^{58,71-73}$ is applied to describe such hybridized interfaces. The model states that there will be a resonance of the molecular states with the metal continuum of states that then gives rise to a shift and Lorentzian function broadening of both the HOMO and LUMO introducing a continuous density of states within the band gap, occupied up to the so-called charge neutrality level (CNL) calculated by integrating the local density of states. The hybridized interface energetics is determined by the relative position of the organic molecular CNL and the underlying substrate work function, which is modified by the interface screening slope parameter $\mathrm{S}$, representing the strength of the interaction. The energy level alignment is shown in Fig. 3.7. The resulting interface energetics, $\Phi_{\text {org/sub }}$ and induced dipole $\Delta$ can be expressed as ${ }^{58}$

$$
\begin{aligned}
& \Phi_{\text {org } / \text { sub }}-\mathrm{CNL}=\mathrm{S}\left(\Phi_{\text {sub }}-\mathrm{CNL}\right) \\
& \Delta=(1-\mathrm{S})\left(\Phi_{\text {sub }}-\mathrm{CNL}\right) \\
& \mathrm{S}=d \Phi_{\text {org } / \text { sub }} / d \Phi_{\text {sub }}=1 /\left(1+4 \pi e^{2} D\left(E_{F}\right) d / A\right)
\end{aligned}
$$

Where $\mathrm{D}\left(\mathrm{E}_{\mathrm{F}}\right)$ is the density of states of the interface molecules at the Fermi level, $\mathrm{d}$ is the distance between the molecule and the underlying substrate, and $\mathrm{A}$ is the interface area of the molecule. 


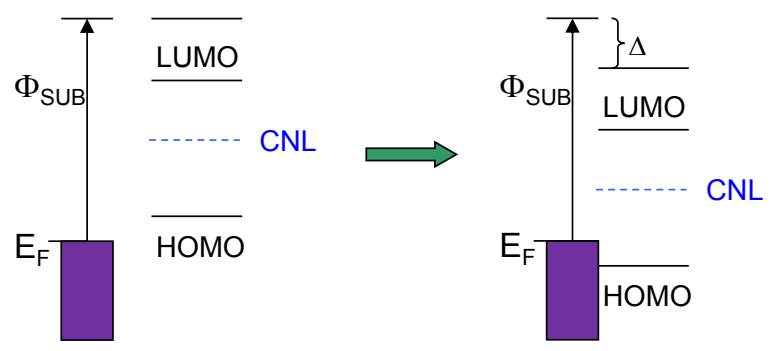

Fig. 3.7 Energy level alignment of organic-metal interface as per IDIS model.

The IDIS model is also used to predict the energy level alignment at organic-organic interface if the same assumptions of a Lorentzian broadening of molecular orbital energies through hybridization are adopted. Charge transfer occurs from the high CNL in one side to the low $\mathrm{CNL}$ on the other side of the heterojunction until equilibrium is achieved. In this case, the slope parameter $\mathrm{S}_{\mathrm{oo}}$ is used to replace the $\mathrm{S}$ at organic-metal interface and the interface dipole $\Delta_{\mathrm{oo}}$ also depends on $\mathrm{S}_{\mathrm{oo}}$ and the initial offset of the two CNL levels (Fig. 3.8): ${ }^{72}$

$\left(\mathrm{CNL}_{1}-\mathrm{CNL}_{2}\right)_{\text {final }}=\mathrm{S}_{\mathrm{oo}}\left(\mathrm{CNL}_{1}-\mathrm{CNL}_{2}\right)_{\text {initial }}$

$\Delta_{\mathrm{oo}}=\left(1-\mathrm{S}_{\mathrm{oo}}\right)\left(\mathrm{CNL}_{1}-\mathrm{CNL}_{2}\right)_{\text {initial }}$

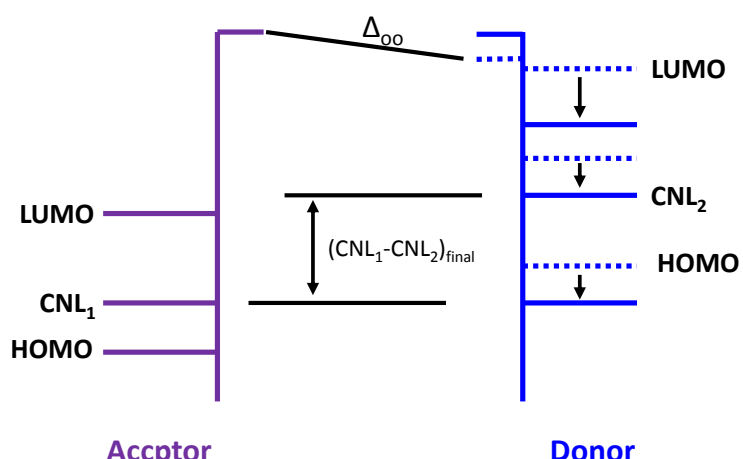

Fig. 3.8 Energy level alignment at organic-organic interface as per IDIS model. Adapted from Reference $^{72}$

Intermolecular hybridization model at donor-acceptor interface: Another model based on intermolecular hybridization at donor-acceptor interface has recently been proposed by Koch et $\mathrm{al}^{74}$. The key of the model is that frontier molecular orbital hybridization between the 
donor HOMO and the acceptor LUMO occurs, leading to the formation of intermolecular states with a reduced energy gap between a doubly occupied bonding and an unoccupied antibonding hybrid orbital (Fig. 3.9). This energy level splitting is captured on the intermolecular resonance integral $\beta$ (or referred to as transfer integral $t$ ), and not only depending on the energy level difference of the individual donor and acceptor, but also on structure of their molecular orbitals, and, finally, on their relative orientation at interface ${ }^{75}$.

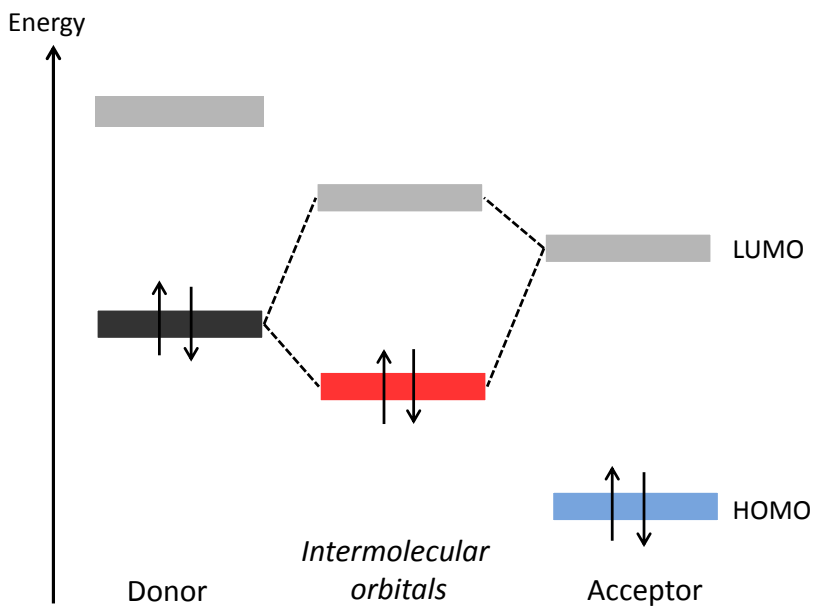

Fig. 3.9 Intermolecular hybridization at donor-acceptor interface.

The hybridization results in three-component system of donor, acceptor and intermolecular complex at the donor-acceptor system (Fig. 3.9). The hybridization induced sub-gap absorption shifts absorption intensity to higher wave lengths, and it is suggested that the intermolecular orbitals form a barrier to geminate recombination in way similar to a small insulating tunneling barrier or a cascading energy level in ternary architecture, enhancing the probability for the charges to escape their mutual Coulomb potential ${ }^{76}$.

\subsection{Strongly interacting interfaces}

Strongly interacting interface in which there is a chemical reaction (chemisorption) at interface often occurring at reactive metal (alkali or alkaline)-organic interface ${ }^{77-79}$. The chemical bonding between the metal and organic semiconductor undergoes a net transfer of charge causing the vacuum level shift introduced by interface dipole, and the up- or downshift depends on the electron transfer direction between the two components, which is 
controlled by their chemical potentials ${ }^{14}$. Currently, it is hard to model the energetics for this type of interface, and its energy level alignment is typically obtained experimentally. Perhaps, one fruitful approach is to view the combination of metal and the chemical reaction layer as the "new substrate". Only when the organic molecule contacts with the reactive metal at interface region, the chemisorption and the strong molecular orbital modification occur, and the rest of organic molecules in the film far away from the interface are as unperturbed, as they had been physisorbed on a new created nonreactive substrate. Hence, the ICT model can be applied to describe the energy level alignment where the new $\Phi_{\text {sub }}$ is reset. However, the real interface remains complex since the strength of chemical reaction, the diffusion distance between metal atom and organic molecule, as well as the intrinsic dipole should be considered $^{10,14,19}$. 


\section{Chapter 4. Photoelectron Spectroscopy and X-ray Absorption Spectroscopy}

The main experiments in this thesis are carried using photoelectron spectroscopy (PES), a useful tool to probe the energetics at organic-metal and organic-organic interfaces and to study their bulk and surface chemical states in a single measurement method. PES includes both traditional X-ray photoelectron spectroscopy (XPS) and ultraviolet photoelectron spectroscopy (UPS), and it is non-destructive to organic semiconductor materials and extremely surface sensitive with detection depth of several nanometers. Additionally, another technique, X-ray absorption often also referred to as near edge absorption fine structure (NEXAFS) with polarized, monochromatized synchrotron radiation light is useful for the investigation of molecular orientation (e.g. preferentially edge-on or preferentially plane-on), which affects the energetics of the organic semiconductor film. All measurements (XPS, UPS and NEXAFS) are performed in an ultra-high vacuum system with a base pressure of $10^{-10}$ mbar to avoid significant electron collision and surface contamination. In this thesis for PES the energy distribution of the emitted photoelectrons at one fixed excitation energy is analyzed at the home equipment, for NEXAFS the absorption of X-rays as a function of photon energy is monitored at beam line D1011 of the MAX-II storage ring at the MAX lab.

\subsection{Basics of photoelectron spectroscopy}

The principle of PES is based on the photoelectric effect ${ }^{25,80}$. Light with an energy $h v$ incident on the isolated molecule is absorbed, whereupon an electron of kinetic energy $E_{k}$ is emitted from the molecule upon photoionization process following the physical process:

$M_{0}+h v \rightarrow M_{+}^{*}+e^{-}$

$\mathrm{M}_{0}$ represents the isolated neutral molecule in the ground state, $\mathrm{M}_{+}^{*}$ the positive molecular ion in the excited state and $\mathrm{e}^{-}$the photoemitted electron. In the same way, their energy relation can be written as

$E_{0}+h v=E_{+}^{*}+E_{k}$ 
Where $E_{0}$ and $E_{+}^{*}$ account for the total energy of the neutral molecule and the ionized molecule, respectively. The photoelectron kinetic energy distribution $E_{k}$ is measured in order to deduce the binding energy $\mathrm{E}_{\mathrm{B}}^{\mathrm{V}}$ related to the Vacuum level as follows:

$E_{B}^{V}=E_{+}^{*}-E_{0}=h v-E_{k}$

This equation is used for interpreting PES. $\mathrm{E}_{\mathrm{B}}^{\mathrm{V}}$ thus corresponds to the energy difference between the initial ground $\left(\mathrm{E}_{0}\right)$ and various final excited states $\left(\mathrm{E}_{+}^{*}\right)$. During the photoelectron emission process, there are electronic relaxation effect occurring. Generally a photoemitted electron can leave the molecule within $10^{-15} \mathrm{~s}$. In the process of intramolecular relaxation the remaining electrons screen the hole in the order of $10^{-16} \mathrm{~s}$ while the nuclear geometric relaxation time is roughly $10^{-13} \mathrm{~s}$, which means that the hole is fully screened but the nuclei are frozen, so that the binding energy shifts to lower values ${ }^{13,51}$. For molecular solids, intermolecular relaxation also happens via the electronic polarization of the surrounding molecule and further helps to screen the hole, causing the additional electron binding energy shift to lower values as compared to the case of gas phase. The schematic picture of PES exhibiting photoelectron emission event is shown in Fig. 4.1.

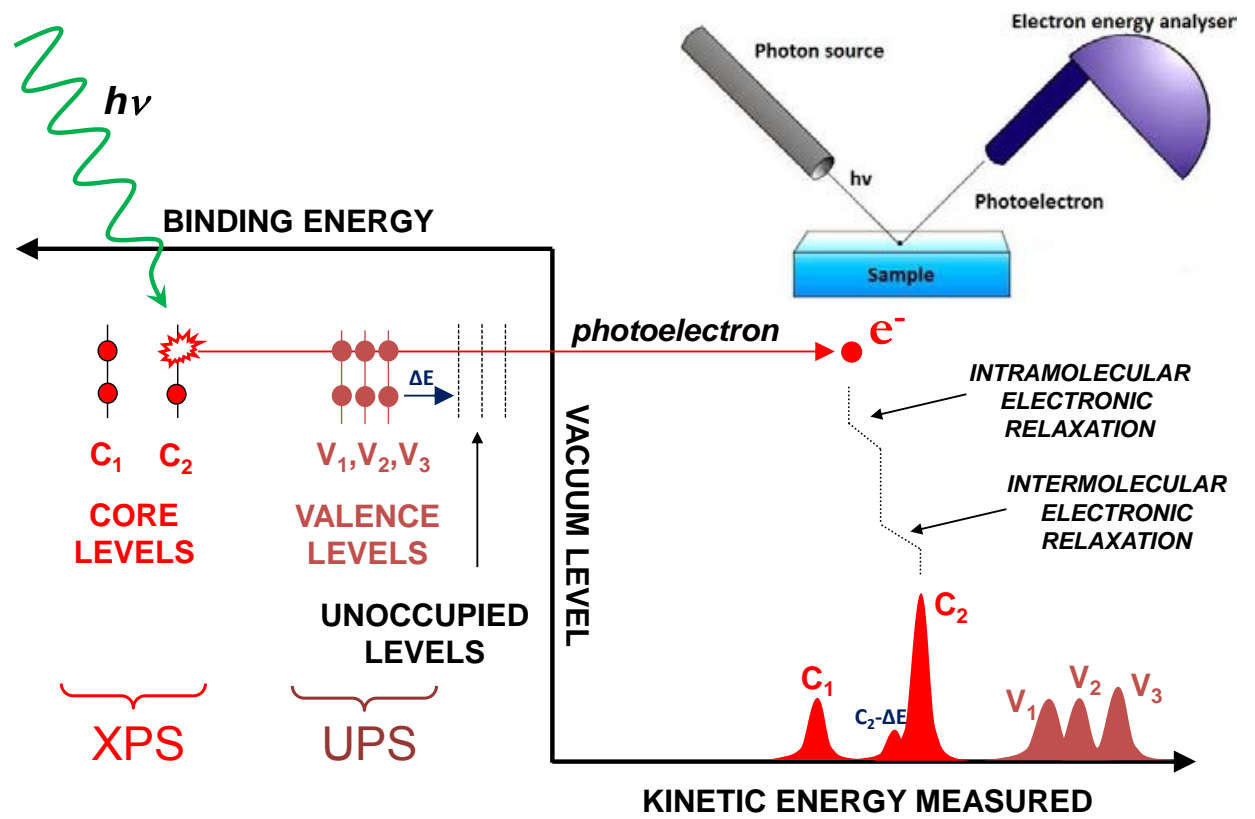

Fig. 4.1 Schematic drawing of PES exhibiting photoemission process including XPS and UPS. The inset indicates the basic working principle of PES. Adapted from Reference ${ }^{51}$ 
The resulting PES spectra in fact include contributions from all possible final states $\mathrm{E}_{+}^{*}$ corresponding to the initial ground state, leading to a break down of the one-electron picture. Fig. 4.2 illustrates the most common final states created upon photoionization. On-set ionization corresponds to the ionization of electron populating the highest valence level (UPS), and the process of an ejected electron from a deep core level is referred as the core level ionization (XPS). The most pronounced PES features originate from the two final states. In shake up process ${ }^{81}$, the photoionization includes exciting another electron to the unoccupied level, leading to decrease in the $E_{k}$ of the photoemitted electron and the observation of some low intensity peaks, e.g $\mathrm{C}_{2}-\Delta \mathrm{E}$, (general a less probable process) accompanying main peak in Fig. 4.1. If the photoionization induces Auger emission, the final states is different as the molecule becomes doubly ionized ${ }^{82}$.

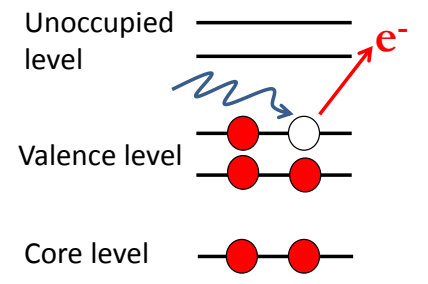

(a) on-set ionization

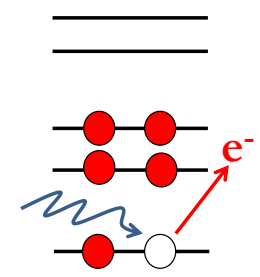

(b) core level ionization

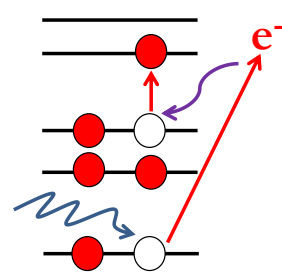

(c) shake-up

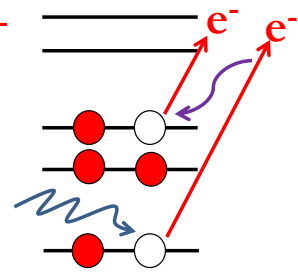

(d) shake-off

Fig. 4.2 Various final states associated with the photoionization.

In PES the electron mean free path is a basic parameter for describing the surface sensitivity and defines the average distance that a (photoemitted) electron can travel through particular medium without suffering energy loss by inelastic scattering. In other words, it can provide an indication of the PES detecting depth and consequently only electron originating from a narrow region at the surface can reach the analyzer without energy loss. The electron mean free path depends on in general the kinetic energy of photoelectrons as displayed in Fig. 4.3, but the exact shape of the curve depends on the medium as evident from the figure. Limited by the electron mean free path even under high kinetic energy, PES is a very useful surface sensitive technique to probe into the electronic structure and the composition of solid surfaces and thin films. Generally, in the case of XPS with $\mathrm{Al}_{\mathrm{K} \alpha}(\mathrm{h} v=1486.6 \mathrm{eV}), 95 \%$ of the signal 
intensity comes from the top $\sim 100 \AA$ of the film. The detection depth of UPS with HeI (hv = $21.22 \mathrm{eV}$ ) is even more surface sensitive, about $10 \AA$.

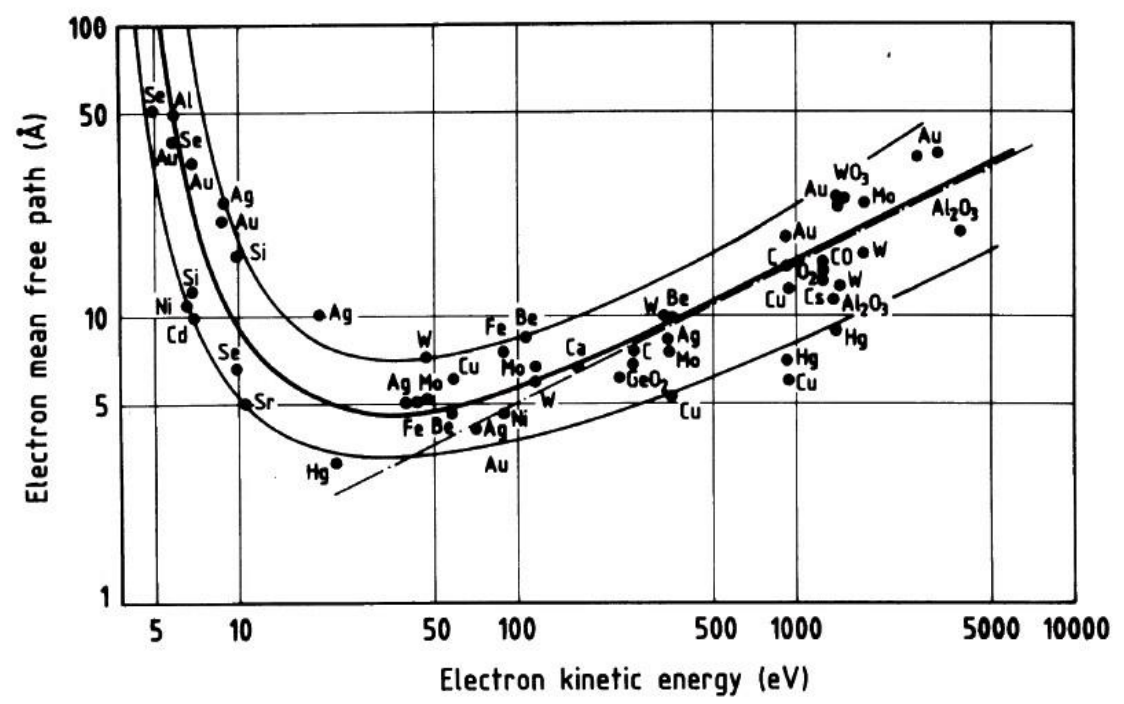

Fig. 4.3 Inelastic electron mean free path (escape depth) as a function of initial kinetic energy. Figure from Reference ${ }^{83}$

\subsection{Ultraviolet photoelectron spectroscopy (UPS)}

UPS likely is the most important method applied to study the energetics at organic-metal and organic-organic interfaces. The photon source is typically a helium resonance lamp with HeI $(\mathrm{h} v=21.22 \mathrm{eV})$ or HeII $(\mathrm{h} v=40.08 \mathrm{eV})$, and the full width of half maxima (FWHM) is as narrow as $30 \mathrm{meV}^{84}$. Such low energy allows a comparatively high cross section for mapping out not only the valence electronic structures of organic semiconductor but also other interface parameters like work function $\Phi$, the vertical ionization potential IP and hole injection barrier $\left(\Phi_{\mathrm{h} \text {,barrier }}\right)$ as well as vacuum level shift $(\Delta)$ as shown in Fig. 4.4. The work function $\Phi$ is a very important factor determining the minimum energy necessary to remove an electron from the material. Its value can be derived from the directly measured energy of the secondary electron cutoff $\left(\mathrm{E}_{\text {cutoff }}\right)$ where it is the position of zero kinetic energy:

$\Phi=h v-E_{\text {cutoff }}$ 
For organic semiconductor film, the ionization potential (IP) derived from UPS, where the nucleic relaxation effect following ionization process is neglected, is known as vertical $\mathrm{IP}^{13}$. In a simplified picture it corresponds to the energy difference between the HOMO level and the vacuum level. Hole injection barrier $\left(\Phi_{\mathrm{h}, \text { barrier }}\right)$ can be simply defined as the energy offset between the Femi level and the HOMO level, which in theory can be directly obtained in a UPS measurement. Upon deposition of organic semiconductor on a solid surface, if the work function changes (vacuum level shift), the potential step $\Delta$ at interface can be tracked by UPS as well. Therefore, as per the information measured by UPS, the interface energetics at heterojunction is obtained and the energy level alignment can be drawn. Obviously, the LUMO level cannot be measured by UPS due to the absence of electrons, hence the inverted photoelectron spectroscopy (IPES) is employed to obtain this energy ${ }^{85,86}$; IPES, however, has inherent problems of sample damage and relatively poor energy resolution ${ }^{87}$, so cyclic voltammetry or ultraviolet-visible absorption spectroscopy in combination with UPS instead is often used to estimate the LUMO level.
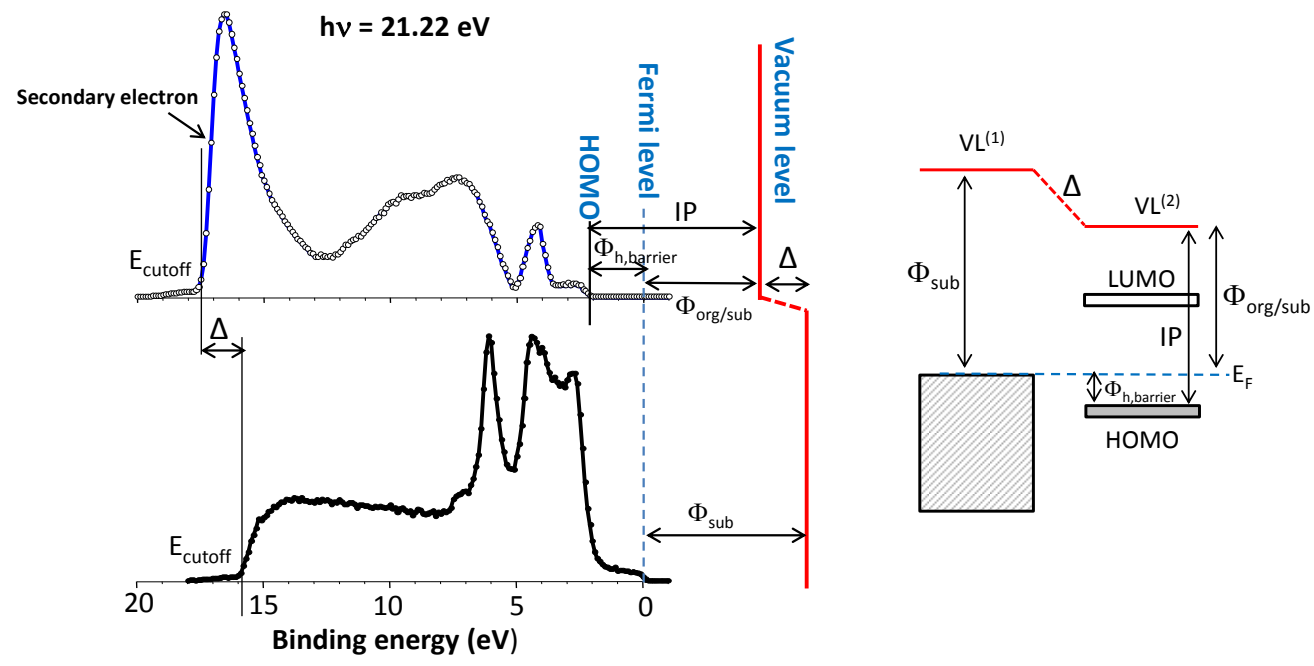

Fig. 4.4 Typical energy level alignment diagram of polymer/conducting substrate interface characterized by UPS. The bottom shows the UPS of conducting substrate and the top shows the UPS of the conjugated polymer on substrate. Example: PFO on Au. Adapted from Reference ${ }^{88}$ 


\subsection{X-ray photoelectron spectroscopy (XPS)}

The commonly used X-ray lines of XPS are $\mathrm{Mg}_{\mathrm{K} \alpha}(\mathrm{h} v=1253.6 \mathrm{eV})$ and monochromated $\mathrm{Al}_{\mathrm{K} \alpha}(\mathrm{h} v=1486.6 \mathrm{eV})$ with $\mathrm{FWHM}$ of about 0.8 and $0.4 \mathrm{eV}$ respectively ${ }^{84}$, which is larger than that of UPS. The high photon energy gives access to the deep-lying core levels as well as to the valence region. Because each element has a unique binding energy, the information on the chemical composition of the surface region can be obtained, and even enables the possibility of quantitative analysis using atomic sensitivity factor (ASF) ${ }^{89}$ which also is limited in its exactness due to inelastic scattering of electrons and cross section effects. The significant shift in the element core level binding energy is called chemical shift ${ }^{90}$, which reflects the chemical environment of the atom such as charge transfer and chemical reaction. XPS thus proves to be highly useful tool to study possible chemical interactions at an interface especially for the case of strongly interacting interfaces mentioned in section 3.5. In Fig. 4.5, XPS Mo3d core level spectral evolution at $\mathrm{MoO}_{3} / \mathrm{Mg}$ :Bphen interface is depicted ${ }^{91}$, The $\mathrm{Mo}^{5+}$ state decreases with incremental $\mathrm{MoO}_{3}$ deposition, which can be seen by comparing the relative content with the main $\mathrm{Mo}^{6+}$ state. It implies the existence of a chemical reaction at the $\mathrm{MoO}_{3} / \mathrm{Mg}$ :Bphen interface due to reduction of $\mathrm{Mo}^{6+}$ cations by charge transfer from $\mathrm{Mg}$.

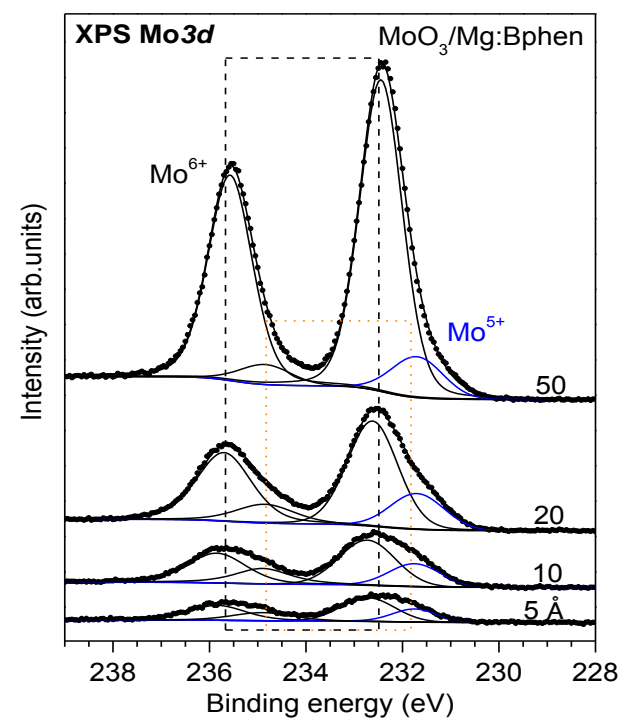

Fig. 4.5 Evolution of XPS Mo3d core level spectra at $\mathrm{MoO}_{3} / \mathrm{Mg}$ :Bphen interface. Adapted from Reference ${ }^{11}$ 
In addition, XPS can also offer the ability to determine the film thickness by monitoring the attenuation of intensity of the underlying substrate due to organic layer coverage according to ${ }^{92}$ :

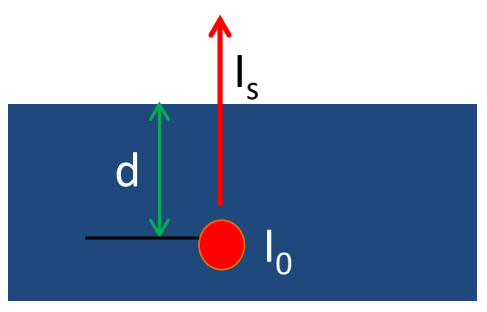

$I_{s}=I_{0} e^{-d / \lambda}$

Where $I_{s}$ is the attenuated intensity, $I_{0}$ is the original intensity, $d$ is the organic film thickness we want to know and $\lambda$ is the electron mean free path in Fig. 4.3.

\subsection{X-ray absorption spectroscopy}

Near edge X-ray absorption fine structure (NEXAFS) spectroscopy is a powerful tool that provides information on the unoccupied electronic structure and molecular orientation ${ }^{27,93}$. Normally, for low- $Z$ elements ( $Z$ is the atomic number) NEXAFS is performed on the K-edge or L-edge in the binding energy range below $1000 \mathrm{eV}^{93}$. The excitation of e.g. a K-shell electron by X-ray source from synchrotron radiation results in either a bound state or a continuum state. Bound state excitation takes place as either Rydberg transitions or excitations of $1 \mathrm{~s}$ electrons to unfilled molecular orbitals labeled as $\pi^{*}$ - or $\sigma^{*}$ - orbitals according to their symmetry. Fig. 4.6 illustrates the corresponding diagram. A $1 \mathrm{~s} \rightarrow \pi^{*}$ transition occurs at energy less than the vacuum level, and a $1 \mathrm{~s} \rightarrow \sigma^{*}$ transition is found at higher energy above the vacuum level. It is stressed that a $1 \mathrm{~s} \rightarrow \pi^{*}$ transition or $\pi^{*}$ resonance can only exist for molecules with $\pi$ bonding, such as double and triple bonds. In the Carbon K-edge NEXAFS spectra of spin-coated rr-P3HT on gold (Fig. 4.7, 90 normal incident), the peak at $285 \mathrm{eV}$ is related to the transition from $\mathrm{C} 1 \mathrm{~s}$ to the empty $\pi^{*}$ states. The feature at around $287 \mathrm{eV}$ is the transition from $\mathrm{C} 1 \mathrm{~s}$ to the $\sigma^{*}$ states of a combination of C-S, C-H and Rydberg excitations ${ }^{94}$. The features located at 292 and $302 \mathrm{eV}$ are associated with the $1 \mathrm{~s} \rightarrow$ $\sigma^{*}$ of $\mathrm{C}-\mathrm{C}$ and $\mathrm{C}=\mathrm{C}$ bonds, respectively. The intensities of these peak shapes correlate linearly to the stoichiometric bond densities with the measured sampled volume. 


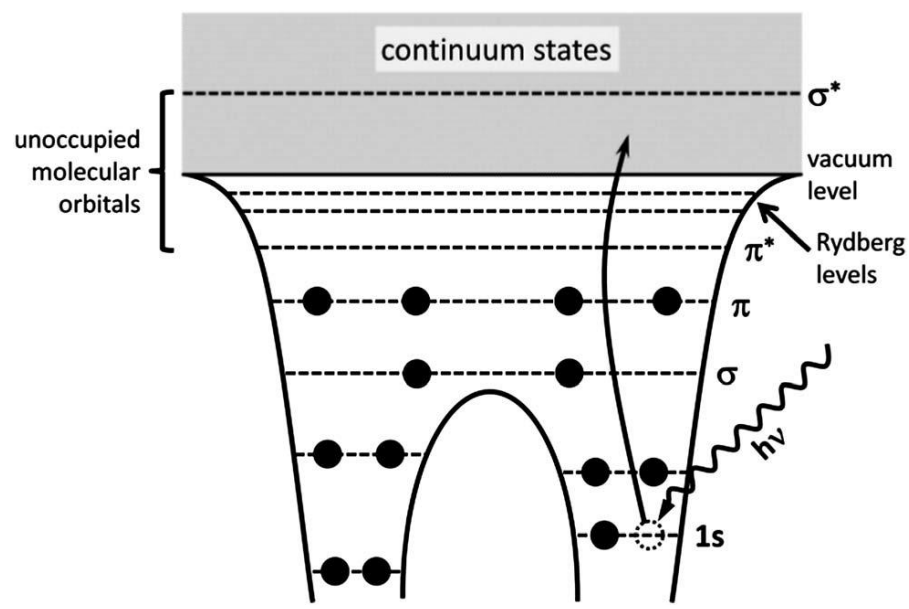

Fig. 4.6 NEXAFS resonant excitation process. Adapted from Reference ${ }^{95}$

In this thesis, NEXAFS is mainly used to determine molecule orientation (preferentially edge-on or preferentially plane-on) because of the strong link between molecular orientation and energetics in organic semiconductor films. By taking NEXAFS measurements at two or more angles of incidence of the X-rays related to the sample surface, the spatial orientation of an orbital can be extracted. Possible core excitation into empty states is governed by the direction of the electric vector $\mathrm{E}$ of the linearly polarized synchrotron radiation. Thus, $\pi^{*}-$ orbitals have a maximum amplitude when the $\mathrm{E}$ is normal (orthogonal) to the bond direction whereas the $\sigma^{*}$ orbitals have maximum amplitude when the $\mathrm{E}$ is along (parallel to) the bond axis. In the collected spectra the relative intensities of excitations into either the $\pi^{*}$ or the $\sigma^{*}$ orbitals hence are a function of the angle of incidence of the linearly polarized synchrotron radiation. Fig. 4.7 depicts the angular dependent C K-edge NEXAFS spectra of spin-coated rr-P3HT on gold, in other words, the spectra weight related to the $\pi^{*}$ states decrease as decreasing the incidence angle and the molecular orientation is the tilted edge-on ${ }^{96}$. 


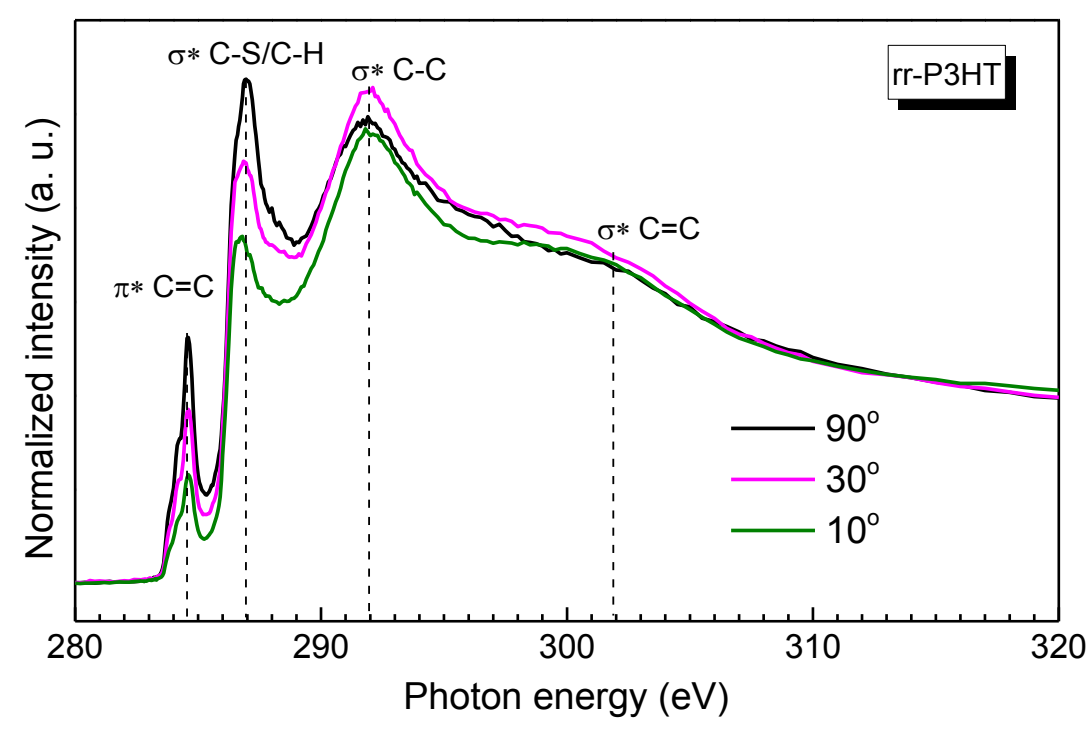

Fig. 4.7 Angular dependence of C K-edge NEXAFS spectra of rr-P3HT film coated on gold with xray beam at $90^{\circ}$ (normal incident), $30^{\circ}$ and $10^{\circ}$ (grazing incident) related to the sample surface. Adapted from Reference ${ }^{97}$ 


\section{Chapter 5. Operation Principles of Organic Solar Cell}

Organic solar cell utilizing $\pi$-conjugated organic semiconductor is considered as a promising renewable energy technology that has attracted widespread interest in both the academic and the commercial communities. The first organic solar cell consisting of a single organic semiconductor sandwiched by two electrodes was presented and investigated before $1986^{98}$, but the field of organic photovoltaics took a major breakthrough with the bilayer structure introduced by Tang at Kodak in that year ${ }^{99}$. The concept of donor-accepter heterojunction facilitates exciton separation where the appropriate energy offset between the LUMO levels of the two materials provides the driving force to exceed at least the exciton binding energy, and thus dramatically improves the photovoltaic performance ${ }^{21}$. However, if the offset is too large, substantial energy loss occurs and the overall efficiency of organic solar cell suffers. The main limitation of the bilayer solar cell is the short exciton diffusion length (10-20 $\mathrm{nm})^{100-103}$, which is conflicting with the thick absorption polymer layer $(\sim 200 \mathrm{~nm})$.

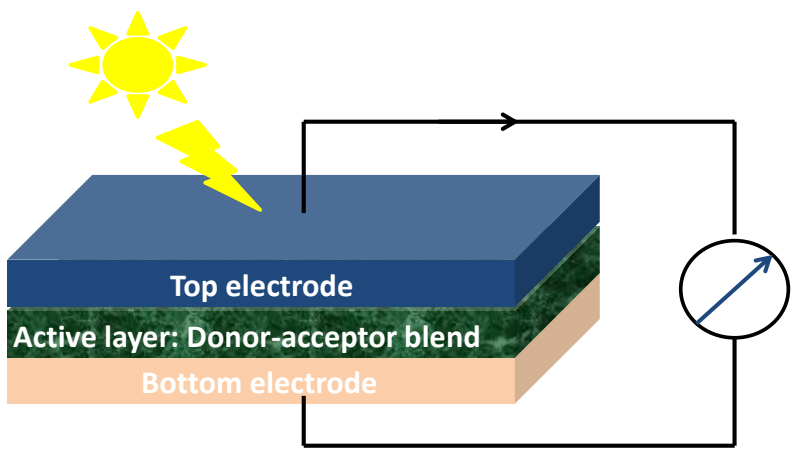

Fig. 5.1 The simplified BHJ solar cell architecture. In the early single-layer and bilayer structures, the active layers are constructed with a single organic semiconductor, and the two layers containing single donor and acceptor organic semiconductor, respectively.

As a result, most of the photogenerated excitons cannot reach a heterojunction interface and dissociate into free charges, leading to a limited photocurrent. In 1991, this problem was solved using the bulk heterojunction $(\mathrm{BHJ})$ structure introduced ${ }^{104}$ in which the donor and acceptor materials were co-deposited together creating a blend in a bulk volume (Fig. 5.1). Such nanoscale interpenetrating network makes the donor-acceptor phase interface within a distance less than the exciton diffusion length and largely increases the interface area, 
consequently, a large fraction of the excitons can be dissociated into free charges and the device efficiency is significantly improved. Currently, the BHJ structure is dominant and widely used in fabricating organic solar cell device with the rapidly rising energy conversion efficiency of up to $11 \%$ for single-junction cell ${ }^{8,9}$. Moreover, the ternary BHJ structure composed of two donors and one acceptor also starts to be studied in order to enhance the light absorption and suppress charge recombination by creating the cascade energy levels ${ }^{105}$.

Depending on the deposition order of anode and cathode in organic solar cell, conventional BHJ solar cell features a bottom indium tin oxide (ITO) modified by PEDOT:PSS with high work function as anode and a top low work function metal as cathode, contrarily, inverted device features a low work function interlayer, e.g. transition metal oxide ( $\mathrm{ZnOx})$, conjugated polymer (PFN), or insulator (PEIE) coated on ITO that acts as the bottom cathode and an airstable high work function metal or metal oxide, e.g. Au and MoOx as the top anode ${ }^{106,107}$. The latter case on the one hand raises the operation lifetime, on the other hand, matches well with the vertical phase separation of BHJ layer and thus enhances charge collection at the organic-electrode interface.

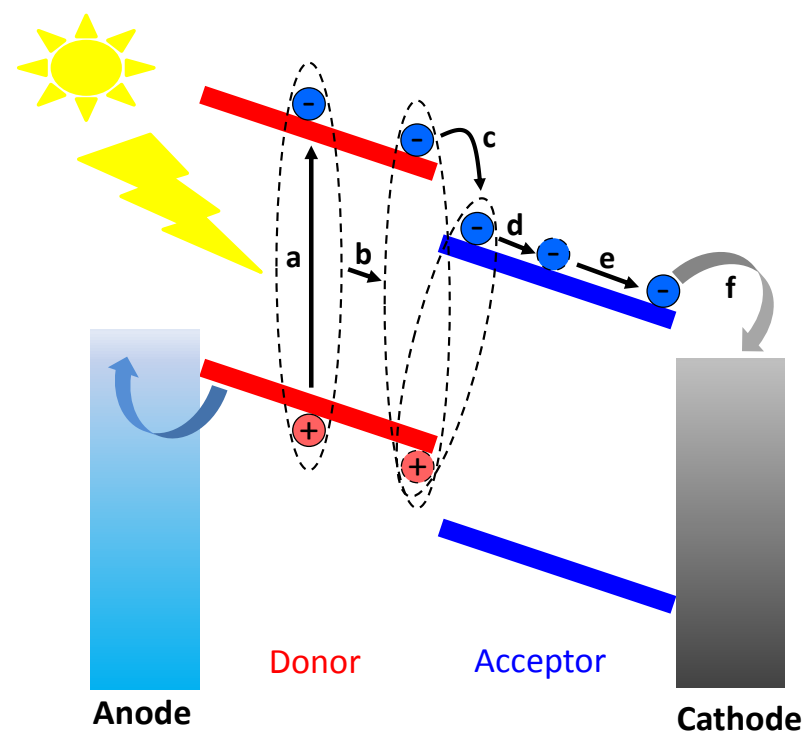

Fig. 5.2 Schematic illustration of the fundamental process of BHJ solar cell.

During the operation of organic solar cell, the fundamental conversion process from light into electricity in a BHJ solar cell can be schematically described by steps of (Fig. 5.2): (a) 
exciton creation through light absorption in the active layer, (b) exciton diffusion to the donor-acceptor interface, (c) exciton dissociation and charge-transfer (CT) exciton formation bound by Coulomb force, (d) CT exciton dissociation into free charge carrier, (e) charge carrier transport towards electrodes, (f) charge carrier collection at electrode interface, producing photocurrent.

Light absorption is controlled by the band gap of the active layer. In order to enhance the number of absorbed photons, the band gap of organic semiconductor should be narrow to capture as much as possible of the solar spectrum. However, the smaller band gap causes much energy loss due to the thermalization process when the higher energy photons are absorbed. Therefore, a trade-off exists between the quantity of the photons absorbed and the absorbed photon energy, pointing to an optimized band gap of 1.1-1.3 eV as suggested by the Shockley-Queisser limit ${ }^{108}$. In addition, the tandem structure with several complementary components is also applied to broaden the total absorption spectrum ${ }^{109}$. The created excitons are strongly bound with a binding energy of up to $0.5 \mathrm{eV}^{110}$ and thermally diffuse to the donor-acceptor interface within a distance less than the excition diffusion length $(10-20 \mathrm{~nm})$ within their lifetime. As noted, if the excitons cannot reach the interfaces, they will instead recombine.

At the donor-acceptor interface, electrons might transfer from the donor excitons to the electronegative acceptor, driven by an energy offset (normally referred as $0.3 \mathrm{eV})^{21}$ between the donor and acceptor LUMO so as to overcome the initial Coulomb binding energy of the excitons. As donor and acceptor molecule phases are physically adjacent to each other at the interface, the dissociated electron-hole pairs are still bound with a significant Coulomb attraction forming so-called charge-transfer (CT) states. It is reported that the binding energy of the CT state is estimated in the range 0.1-0.5 $\mathrm{eV}^{111-113}$, which is larger than the thermal energy $(\sim 0.025 \mathrm{eV})$ at room temperature and thus indicates an energetic barrier that exists for CT exciton dissociation into free charge carrier. The CT exciton separation plays a crucial role in function of the organic solar cell, affecting not only the short circuit current but also open circuit voltage ${ }^{114,115}$. Fig. 5.3 summarizes the photocurrent process involved in CT exciton generation, separation and recombination. The inefficient CT excitons lead to germinate recombination to form either the ground state $\left(\mathrm{K}_{\mathrm{GR}}\right)$ or the triplet exciton $\left(\mathrm{K}_{\text {triplet }}\right)$. At the stage of CT state separation, the two kinetic competitions occur. One is between thermalization and dissociation of the hot $\mathrm{CT}$ states, that is to say that the hot $\mathrm{CT}$ states directly dissociate into charge-separated (CS) states (Kcs*) contributing to charge 
photogeneration, but the hot $\mathrm{CT}$ state can thermally relax to the lowest excited state $\left(\mathrm{K}_{\text {therm }}^{\mathrm{CT}}\right)$. Another competition is between the geminate recombination $\left(\mathrm{K}_{\mathrm{GR}}\right.$ or $\left.\mathrm{K}_{\text {triplet }}\right)$ and dissociation of the relaxed CT state $\left(\mathrm{Kcs}_{0}\right)$ into CS states. The separation distance of electron-hole pairs continuously increases and thus the excitons suffer less Coulombic attraction, finally, the free charge carriers are created beyond the Coulomb force.

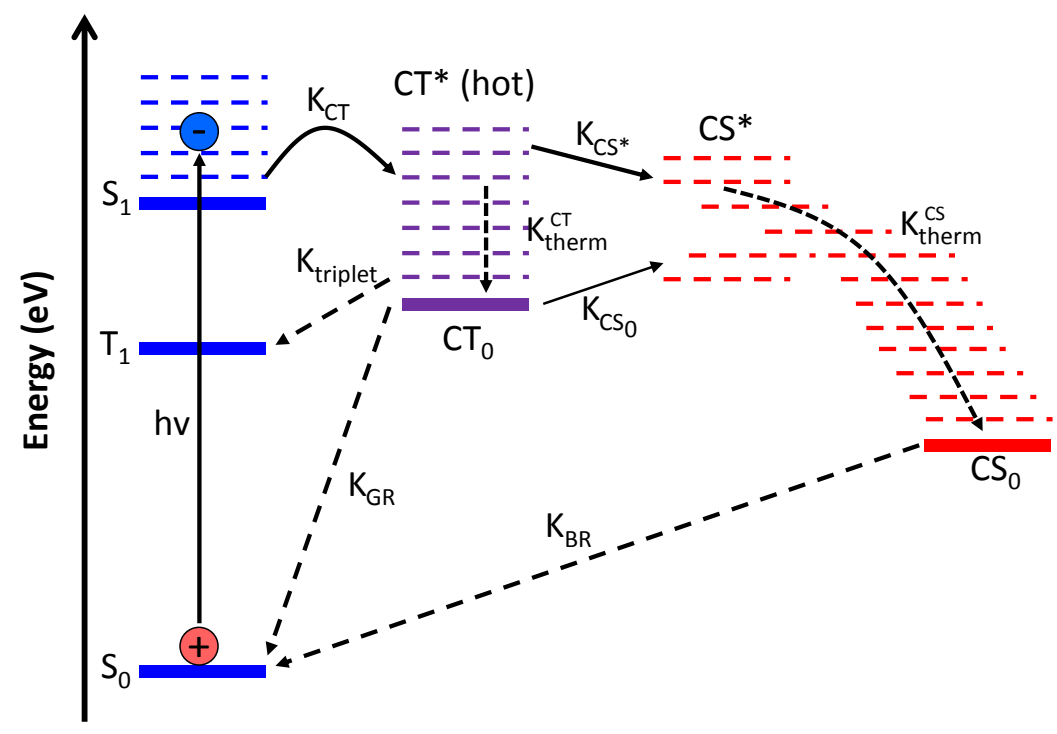

Fig. 5.3 Energy level diagram for CT exciton generation, separation and recombination. Adapted from Reference ${ }^{112}$

During the process of the free charge carrier transport towards electrode for photocurrent generation, several recombination steps generally including bimolecular recombination $\left(\mathrm{K}_{\mathrm{BR}}\right)$, trap-assisted recombination and surface recombination occur that decrease the photocurrent and the overall power efficiency of the device. The former follows the Langevin expression and the rate depends on the probability of free holes and electrons meeting each other ${ }^{116}$. The middle is known as the Schockley-Read-Hall recombination ${ }^{23}$. The trap states are mainly caused by impurities and defects in active layer as well as interfacial states resulted from oxidation/reduction polymer segment. The latter happens on the electrode surface and can be suppressed through surface state cut-down, e.g. passivation treatment and inserting ideal interlayer $^{106,117}$. 


\section{Chapter 6. Summary of Papers Included in the Thesis}

Six publications included in this thesis have given the deeper understanding of interface phenomena regarding both donor-acceptor and active layer-electrode interfaces in BHJ OPVs, which are combined with the ICT model applied both to interface energetics of organic semiconductor and to the design of OPVs in order to improve the efficiency and lifetime.

Paper I proposes new design rules for donor-acceptor interface to optimize open circuit voltage and overall performance of OPVs, in fact enabling not just efficient screening of OSC donor and acceptor materials but also in silico design thereof. Paper II presents research on the two different degradation mechanisms of interface energetics of PCBMelectrode interface caused by oxygen and water, respectively. Paper III proposes a general model for energy level bending in absence of significant doping of conjugated polymer film, showing experimental results that overturn some of the recent models. Papers IV and $\mathbf{V}$ are devoted to the development of a universal model for handling energetics that simultaneously treats doped conjugated polymer and conjugated electrolyte/electrode interface, which are two established methods for improving charge injection/exaction efficiency. Paper VI addresses the effect of processing (and the environment), i.e. UV-light soaking under different conditions, on surface electronic structures of the interlayer $\mathrm{ZnO}$ nanoparticle film and the OPV performance. 


\subsection{Paper I}

Trap-Assisted Recombination via Integer Charge Transfer States in Organic Bulk Heterojunction Photovoltaics

Q. Y. Bao, O. Sandberg, D. Dagnelund, S. Sanden, S. Braun, H. Aarnio, X. J. Liu, W. M. Chen, R. Österbacka, and M. Fahlman

Advanced Functional Materials, 2014, 24, 6309

Charge transfer (CT) complexes play an important influence on the efficiency of bulk heterojunction solar cells. These studies have always focused on the photogenerated CT complexes but the presence and effect of integer charge transfer (ICT) states presented in the dark and created as a consequence of Fermi level equilibrium has all but been ignored so far, despite indications of their significance.

In the Paper I, we use a series of regioregular-poly(3-hexylthiophene):fullerene $\left(\mathrm{C}_{60 / 70}\right.$, $\mathrm{PC}_{60 / 70} \mathrm{BM}, \mathrm{BisPC}_{60} \mathrm{BM}$, TriPC ${ }_{60} \mathrm{BM}$ and $\left.\mathrm{IC}_{60} \mathrm{BA}\right)$ bulk heterojunction solar cells with pinned electrodes to show ICT states are often formed at the bulk heterojunction interface and have a profound effect on the open circuit voltage $\left(\mathrm{V}_{\mathrm{oc}}\right)$. Normally, the donor ionization potential to acceptor electron affinity energy difference is thought to be an upper limit of the device $V_{o c}$, but the effective energy gap should include possible potential steps at the bulk heterojunction that is the relevant parameter. The experiments reveal that the ICT state formation causes vacuum level misalignment that yields a roughly constant effective donor ionization potential to acceptor electron affinity energy difference at the series of rr-P3HT:fullerene interfaces, even though there is a large variation in the fullerene series' electron affinity. This is a radical departure from common wisdom, which e.g. holds that the improved $\mathrm{V}_{\text {oc }}$ using $\mathrm{IC}_{60} \mathrm{BA}$ as compared to $\mathrm{PC}_{60} \mathrm{BM}$ in combination with rr-P3HT is due to a better matching between the energy levels of rr-P3HT and those of the fullerene. We highlight that the large variation in $\mathrm{V}_{\mathrm{oc}}$ for the device series featuring different fullerenes instead is found to be a consequence of variations in trap-assisted recombination via ICT states, and we demonstrate this holds true if one assumes a pn junction or metal-insulator-metal based description of bulk heterojunction solar cells. Electron paramagnetic resonance measurements confirm the creation of ICT states at the bulk heterojunctions in the dark and together with photo-assisted absorption measurements show that the donor/acceptor coupling strength and recombination-induced loss can be predicted as per the ICT model. The results enable us to propose novel design 
rules for the donor/acceptor materials using measured or DFT calculated ICT states for bulk heterojunction solar cells:

(i) Pinned electrode contacts are obtained by: $\Phi_{\text {anode }} \geq \mathrm{E}_{\mathrm{ICT}+, \mathrm{D}}$ and $\Phi_{\text {cathode }} \leq \mathrm{E}_{\mathrm{ICT}-\mathrm{A}}$

(ii) Donor:acceptor combinations should be chosen so that $\mathrm{E}_{\mathrm{ICT}-\mathrm{A} \mathrm{A}} \approx \mathrm{E}_{\mathrm{ICT}+\mathrm{D}}$

The design rules are tested against a set of high performing donor polymers and their corresponding fullerene-based OPV devices available in literature, and excellent correlation is obtained. See Fig.6.1.

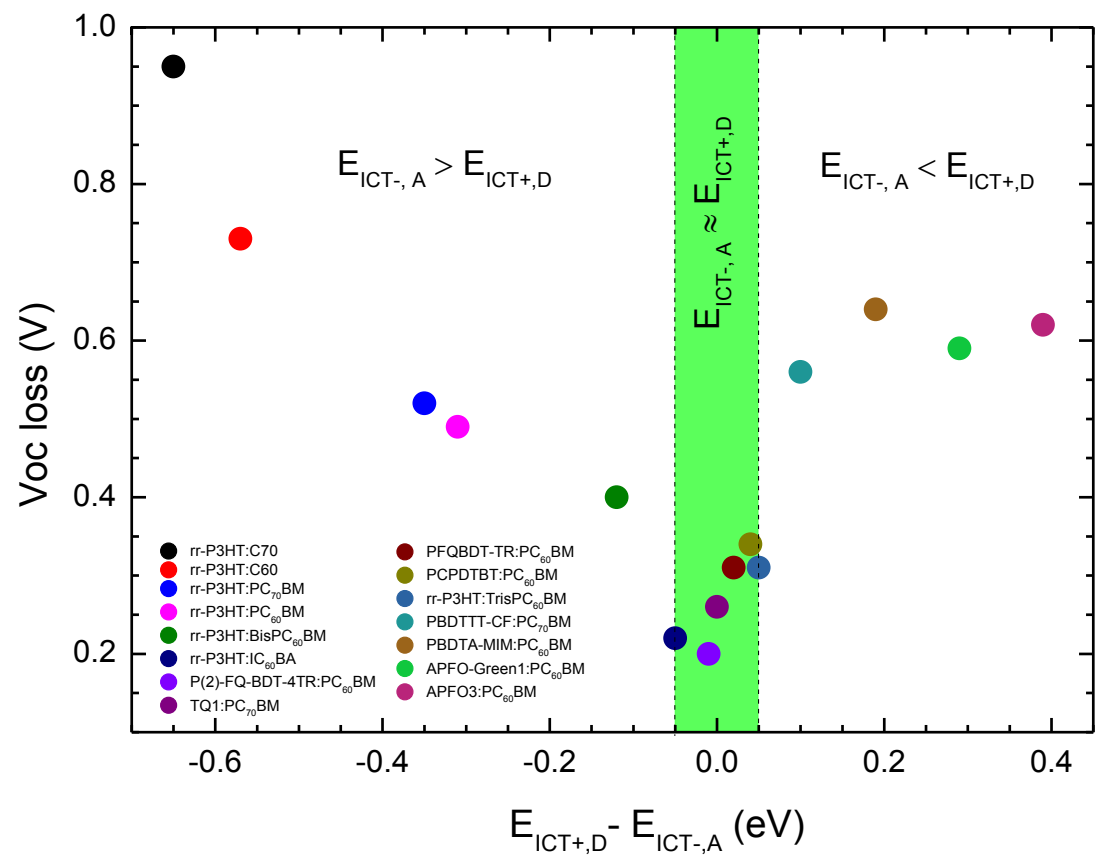

Fig. 6.1 Experimental Voc loss plotted against the $\mathrm{E}_{\mathrm{ICT}+\mathrm{D}}$ (Donor) - $\mathrm{E}_{\mathrm{ICT}-\mathrm{A}}$ (Acceptor) for a set of polymer:fullerene bulk heterojunction solar cells. 


\title{
6.2 Paper II
}

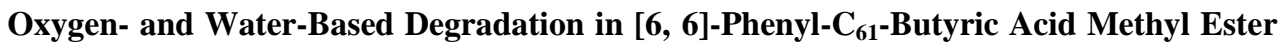 (PCBM) Films}

\author{
Q. Y. Bao, X. J. Liu, S. Braun, and M. Fahlman
}

Advanced Energy Materials, 2014, 4, 1301272

The understanding of degradation mechanism and stability of PCBM film as a common component in OPVs when exposed to atmosphere is expected to aid in further development of both organic semiconductor materials and in device engineering.

In the Paper II, we probe into the effects of in situ oxygen and water vapor separately on the energetics of PCBM films in UHV. The modification of PES features originates from interaction between the fullerene part of PCBM and oxygen or water molecules. The results show that the degradation mechanisms of PCBM film induced by oxygen and water are absolutely different. Upon exposure to oxygen gas, the work function downshifts by $\sim 0.15$ $\mathrm{eV}$ both for pinned ( $\left.\mathrm{E}_{\mathrm{ICT}+/-}\right)$ and vacuum level aligned interfaces compared to the ICT curve of pristine PCBM film, which is incompatible with oxidation/p-doping. We speculate it results from energy level bending due to defect states located above the $\mathrm{E}_{\mathrm{ICT}}$ - level of PCВM, and the other possible explanation is the double dipole model proposed in Paper IV as the negatively charged oxygen species are more mobile than the hole-carrying PCBM. The IP value and UPS spectra features of the PCBM film are not affected and the oxygen degradation effect is reversible by thermal treatment in UHV, indicating a weak interaction between oxygen and PCBM molecules. When exposed to water, water vapor induces the occupied valence structure to undergo irreversible and strong modification (extensive broadening and blending of the frontier features in the UPS spectra) accompanied by the significant change of O1s and C1s XPS core spectra. The work function and IP decrease without a saturation trend within the studied exposure times. This suggests that significant chemical reaction occurs between the water and PCBM. According to these findings, in the case of oxygen induced degradation, a downward energy level bending in PCBM domains at the extracting contact would cause $\mathrm{V}_{\mathrm{oc}}$ loss, whereas it would aid positively free charge generation by sweeping away electrons from the D-A interface. The strong irreversible degradation of the electronic structure from water exposure is likely to negatively affect the transport properties of the PCBM. 


\subsection{Paper III}

The Energetics of the Semiconducting Polymer-Electrode Interface for SolutionProcessed Electronics

Q. Y. Bao, S. Fabiano, M. Andersson, S. Braun, Z. Y. Sun, X. Crispin, M. Berggren, X. J. Liu, and M. Fahlman

(Submitted)

The spatial dependence of energy levels in organic semiconductor film induced by charge transfer across a heterojunction strongly influences charge injection and transport as well as exciton dissociation in organic electronic devices. The current views about energy level bending (ELB) in conjugated polymer films, e.g. experimental observations and models, are largely divergent, which are derived from films fabricated by spin-coating that can easily yield partial coverage/pin hole in the ultrathin film.

In the Paper III, we use the original approach of building and characterizing multilayers composed of a well-defined number of polymer monolayers with the Langmuir-Shäfer method. This allows us to track spatial dependence of ELB at a precision never achieved for semiconducting polymers, avoiding artefacts from spin-coating. The evolutions for both work function and the occupied electronic structures are probed by PES in ultrahigh vacuum and the order in the films is detected by a combination of AFM, NEXAFS and PL techniques. The TQ1 disorder film features smaller, and in fact negligible, ELB compared to the rr-P3HT more well-ordered film, in other words, an increase in local disorder yields a narrower ELB, in contradiction with existing models (Fig. 6.2a). We propose a general model for energy level bending in absence of significant doping of conjugated polymer film (Fig. 6.2c). The study highlights that ELB depends on the distribution of oxidation/reduction energies in the polymer layer compared with the position of the Fermi level, taking into account the Coulomb energy associated with charging the polymer chain and transferring a charge across the interface (Fig. 6.2b). The consequence of this is that almost all the potential shift necessary to equilibrate the Fermi level occurs over the first 1-2 monolayers at an interface (Fig. 6.2c). An extended ELB region featuring a significant potential shift away from the interface may still occur for well-ordered films with delocalized polarons or if there is a strong order-dependence of the organic semiconductor $\mathrm{E}_{\mathrm{ICT}+, . .}$ Under such scenarios more 
extended ELB regions in organic semiconductor films can occur even in absence of significant doping-induced free charge density.

(a)
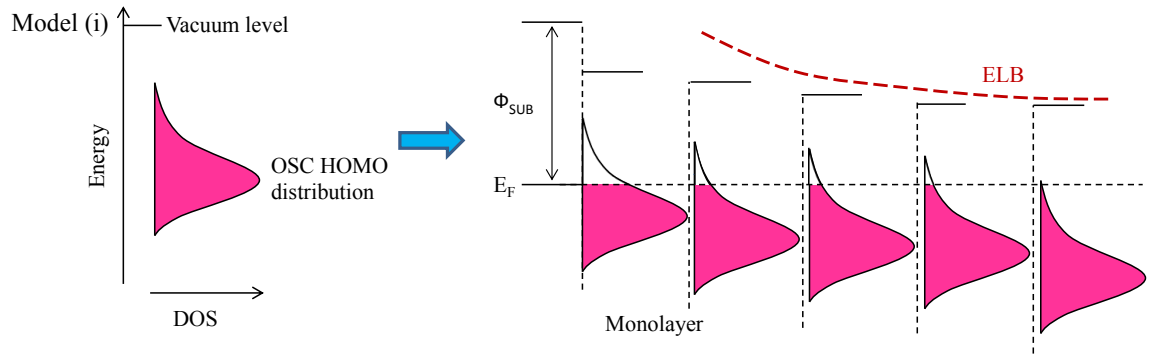

(b)

(c)

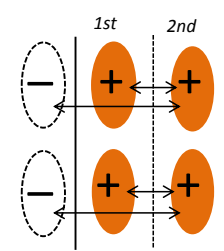

Model (ii)
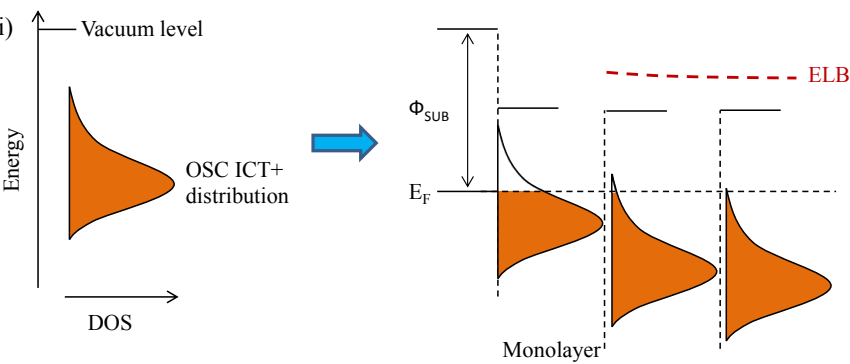

Fig. 6.2 ELB formation mechanism in conjugated polymer film. (a) Model (i) assumes that there is no Coulomb energy associated with charging the polymer chain and transferring a charge across the interface. (b) Coulomb interaction between charges in the polymer layer at interface and the mirror charges across interface. (c) Model (ii) assumes that there is energy related to charging the polymer film including Coulomb interaction between the electron transferred to the substrate and the hole left on the OSC molecule/polymer. Charge transfer occurs when part of the integer charge transfer energy distribution is above the Fermi level. 


\subsection{Paper IV}

\section{Energetics at Doped Conjugated Polymer/Electrode Interfaces}

Q. Y. Bao, X. J. Liu, S. Braun, F. Gao, and M. Fahlman

Advanced Materials Interfaces, 2015, 2, 1400403

Doping has been proved to be a powerful technique able to improve the efficiency of organic electronics by tuning the electronic properties of organic semiconductor. Unlike the case of the pristine organic semiconductor that follows the ICT model, a universal model for energy alignment at molecule-doped conjugated polymer/electrode interface is still not established.

In the Paper IV, the energetics at molecule F4TCNQ doped polycrystalline rr-P3HT and amorphous TQ1 polymer, respectively, with various doping concentrations/conducting substrates interfaces are investigated. Regular plots with a constant thickness-independent displacement away from the original energy level alignment behavior of the pristine polymer at low to intermediate level for molecule-doped conjugated polymer interfaces are observed, and that at high doping level are substrate-independent. We propose an universal model for describing this class of interfaces: (i) equilibration of the Fermi level due to oxidation (or reduction) of polymer sites at the interface as described by ICT model and additionally (ii) a double dipole step induced by image charge from the dopant-polymer charge transfer complex that cause a shift of the work function for both pinned $(\mathrm{S}=0)$ and unpinned $(\mathrm{S}=1)$ interfaces. Such behavior is expected to hold for all low to intermediate level doped polymer systems. For high doping levels (significant density of free charges at the interface), the classic depletion layer model is found to hold. 


\subsection{Paper V}

\section{Regular Energetics at Conjugated Electrolyte/Electrode Modifier for Organic Electronics and Their Implications of Design Rules}

Q. Y. Bao, X. J. Liu, E. G. Wang, J. F. Fang, F. Gao, S. Braun, and M. Fahlman (Submitted)

Conjugated electrolytes (CEs) are very efficient charge injection/extraction interlayers for device operation due to their ability to effectively modify the work function of bare electrodes. CEs feature both $\pi$-conjugated electronic structures and ions, therefore, it is reasonable to expect that $\mathrm{CE} /$ electrode energetics can be described by combination of the ICT model and models based on non-conjugated electrolytes.

In the Paper $\mathrm{V}$, through systematically studying a $\mathrm{CE}$ series with various ionic groups including cationic PFN, TQm8-N, PFNBr, anionic P3CBT and zwitterionic $\mathrm{P}(\mathrm{NSO} 3)_{2}$, a general model for energy level alignment at $\mathrm{CE} /$ electrode interfaces is presented: (i) equilibration of the Fermi level due to oxidation/reduction of $\pi$-delocalized backbone at interface as per the ICT model in combination with (ii) an additional interface dipole step induced by ion migration or side chain electrostatic realignment, which is similar to the results in Paper IV. These models reveal how to manipulate the energetics of CE/electrode interfaces to achieve the smallest charge injection/extraction barriers and bypass the current interlayer thickness limitation: (a) Acceptor (n-type) cationic CEs should be near ideal for designing electron injecting $\mathrm{CE} /$ electrode contacts, as the acceptor nature of these materials enable pinning to the ICT- states even for moderately high work function electrodes $(<4.6$ $\mathrm{eV}$ or so). Pinning in the (i) region of the ICT curve ensures the lowest $\Phi_{e, \text { barrier }}$ and hence efficient electron injection and transport even for thicker CE layers. Anionic CEs should have donor (p-type) $\pi$-delocalized backbones, enabling pinning in the (iii) region under the moderate $\Phi_{e l}$ and the lowest $\Phi_{h, \text { barrier }}$ at the CE/electrode interface regardless of thickness. 


\subsection{Paper VI}

\section{Effects of Ultraviolet Soaking on Surface Electronic Structures of Solution Processed ZnO Nanoparticle Films in Polymer Solar Cells}

Q. Y. Bao, X. J. Liu, Y. X. Xia, F. Gao, L. D. Kauffmann, O. Margeat, J. Ackermann, and M. Fahlman

Journal of Materials Chemistry A, 2014, 2, 17676

The photovoltaic performance has been demonstrated to be sensitive to surface electronic structure of cathode interlayer. $\mathrm{ZnO}$ nanoparticle ( $\mathrm{ZnONP}$ ) film provides well matching contact energetics with the active layer for tuning cathode side.

In the Paper VI, we explore the effect of UV-light soaking on surface electronic structures and chemical states of solution processed ZnONP film in UHV, dry air and UV-ozone. We find that its surface properties are very sensitive to the UV irradiation. UV soaking in UHV induces a slight decrease in both work function and oxygen-deficient component, and an almost negligible downshift in valence band. For UV-light soaking in presence of oxygen, the work function increases accompanied by a smaller energy offset between the valence band edge and Fermi level. A decrease of the oxygen-defect component and a slight increase of the $\mathrm{ZnO}$ matrix feature are observed that is attributed to the desorption of oxygen molecules from the surface and filling of oxygen atoms in the $\mathrm{ZnO}$ matrix. The work function of $\mathrm{ZnONP}$ film can be tuned over a range spanning more than $1 \mathrm{eV}$ using this technique. Deriving from photovoltaic and diode measurements, it is concluded that the high work function ZnONP films retains their n-type behavior as the oxygen vacancy filling from the UV-ozone soaking seems concentrated to the surface of the films. Enhancement in short current density can be obtained as filling of surface vacancies reduce carrier recombination at fullerene/ZnONP interface. 


\section{Chapter 7. Future Outlook}

Photoelectron spectroscopy: PES-derived IP measurement does not take geometrical relaxation contribution to the polaron energy into account and thus is not accurately equated with the charge injection/extraction barrier. In addition, different types of organic electronics utilize different part of the polaron density of states, generally sending to lower carrier concentrations from OTFTs, OLEDs, OPVs to organic spin valves. The relevant part of density of states may be far into the tail states or even is covered up by the normal PES background. Therefore, further achieving the accurate energetics of polaron density states, detecting the tail states with the ultrahigh-sensitivity UPS or modeling, and investigating the effect of tail states on the OPV efficiency that is in fact ignored so far, are of tremendous importance.

Donor-acceptor interface design: A new design rule for donor-acceptor interface based on polymer:fullerene BHJ OPVs to optimize open circuit voltage has been proposed and tested in this thesis. An examination of extending this rule into small molecule blends is in process. As per the rule, tailoring the energy of negative integer charge transfer states of common fullerenes to match with that of high efficiency donor materials is one interesting topic.

Hybridization effect at donor-acceptor interface: Recently OSC doping microscopic mechanisms are controversial between integer charge transfer and hybridization. It means that the latter model makes the frontier orbital hybridization between the donor HOMO and the acceptor LUMO, leading to a strong ground state bleach attributed to the formation of charge-transfer complexes with a reduced energy gap that would capture higher light wave lengths, and create the cascading energy levels enhancing the exciton dissociation. Donoracceptor interface in OPVs following the ICT model has been generally accepted, but hybridization still can occur when the parameters, e.g. the individual energy levels of donor and acceptor materials, the special structure of their frontier orbitals and their relative orientation at interface, are satisfied. This design approach for donor-acceptor interface may have a potential in OPV application.

Selection principle of electrode modifier: Many soft materials have been widely used to tailoring electrode for improving charge injection/extraction efficiency and operation lifetime, and a universal model for energetics of conjugated electrolyte-electrode interface was 
proposed in this thesis. However, the modified work function may originate from push back effect, charge transfer dipole and intrinsic dipole as well as other possible contribution. Unlocking the relation between the chemical structure of material and its interface energetics, finally understanding the selection principle of "green" electrode modifier is necessary. 


\section{References}

1 Zaumseil, J. \& Sirringhaus, H. Electron and ambipolar transport in organic field-effect transistors. Chem. Rev. 107, 1296-1323 (2007).

2 Tang, C. W. \& Vanslyke, S. A. Organic lectroluminescent diodes. Appl. Phys. Lett. 51, 913915 (1987).

3 Yu, G., Gao, J., Hummelen, J. C., Wudl, F. \& Heeger, A. J. Polymer photovoltaic cells enhanced efficiencies via a network of internal donor-acceptor heterojunctions. Science 270, 1789-1791 (1995).

4 Zimmerman, J. D. et al. Porphyrin-tape/C60 organic photodetectors with $6.5 \%$ external quantum efficiency in the near infrared. Adv. Mater. 22, 2780-2783 (2010).

5 Scott, J. C. \& Bozano, L. D. Nonvolatile memory elements based on organic materials. Adv. Mater. 19, 1452-1463 (2007).

6 Riechel, S. et al. Very compact tunable solid-state laser utilizing a thin-film organic semiconductor. Opt. Lett. 26, 593-595 (2001). Dediu, V. A., Hueso, L. E., Bergenti, I. \& Taliani, C. Spin routes in organic semiconductors. Nat. Mater. 8, 707-716 (2009).

8 www.m-kagaku.co.jp.

9 www.heliatek.com.

10 Hwang, J., Wan, A. \& Kahn, A. Energetics of metal-organic interfaces: New experiments and assessment of the field. Mat. Sci. Eng. R. 64, 1-31 (2009). Shoaee, S. et al. Charge photogeneration in donor/acceptor organic solar cells. J. Photon Energy 2, 021001 (2012). Maurano, A. et al. Recombination dynamics as a key determinant of open circuit voltage in organic bulk heterojunction solar cells: a comparison of four different donor polymers. Adv. Mater. 22, 4987 (2010).

13 Fahlman, M. et al. Photoelectron spectroscopy and modeling of interface properties related to organic photovoltaic cells. J. Electron Spectrosc. Relat. Phenom. 190, 33-41 (2013).

14 Ishii, H., Sugiyama, K., Ito, E. \& Seki, K. Energy level alignment and interfacial electronic structures at organic/metal and organic/organic interfaces (vol 11, pg 605, 1999). Adv. Mater. 11, 972-972 (1999).

Koch, N. Organic electronic devices and their functional interfaces. Chemphyschem 8 , 1438-1455 (2007).

16 Greiner, M. T. et al. Universal energy-level alignment of molecules on metal oxides. Nat. Mater. 11, 76-81 (2012).

17 Tengstedt, C. et al. Fermi-level pinning at conjugated polymer interfaces. Appl. Phys. Lett. 88, 053502 (2006).

18 Crispin, A., Crispin, X., Fahlman, M., Berggren, M. \& Salaneck, W. R. Transition between energy level alignment regimes at a low band gap polymer-electrode interfaces. Appl. Phys. Lett. 89, 213503 (2006).

19 Braun, S., Salaneck, W. R. \& Fahlman, M. Energy-level alignment at organic/metal and organic/organic interfaces. Adv. Mater. 21, 1450-1472 (2009).

20 Fahlman, M. et al. Electronic structure of hybrid interfaces for polymer-based electronics. J. Phys-Condens. Mat. 19, 183202 (2007).

21 Scharber, M. C. et al. Design rules for donors in bulk-heterojunction solar cells - Towards $10 \%$ energy-conversion efficiency. Adv. Mater. 18, 789 (2006).

22 Aarnio, H. et al. Spontaneous charge transfer and dipole formation at the interface between P3HT and PCBM. Adv. Energy Mater. 1, $792-797$ (2011). 
23 Bao, Q. Y. et al. Trap-assisted recombination via integer charge transfer states in organic bulk heterojunction photovoltaics. Adv. Funct. Mater. 24, 6309-6316 (2014).

Bai, S. et al. Ethanedithiol treatment of solution-processed $\mathrm{ZnO}$ thin films: controlling the intragap states of electron transporting interlayers for efficient and stable inverted organic photovoltaics. Adv. Energy Mater. DOI: 10.1002/aenm.201401606.

Salaneck, W. R., Strafström, S. \& Bredas, J. L. Conjugated polymer surfaces ansd interfaces: electronic and chemical structure of interfaces for polymer light emitting devices. Cambridge University Press, Cambridge, 1996. electronic and structural properties of thin organic films and liquids. Chem. Soc. Rev. 35, 1244-1255 (2006). 1101 (1977). Pope, M. \& Swenberg, C. E. Electronic Processes in Organic Crystals and Polymers. Oxford University Press, Oxford, 1999. Feng, G. Loss Mechanisms in Bulk Heterojunction Organic Photovoltaics. University of Cambridge ,Ph.D thesis (2011).

Moliton, A. \& Hiorns, R. C. Review of electronic and optical properties of semiconducting conjugated polymers: applications in optoelectronics. Polymer International 53, 1397-1412 (2004).

33 Fahlman, M. \& Salaneck, W. R. Surfaces and interfaces in polymer-based electronics. Surf. Sci. 500, 904-922 (2002).

34 Marsh, R. A. Charge recombination and separation in excitonic photovolatics cells. University of Cambridge ,Ph.D thesis (2009).

Chen, X. L. et al. Ion-modulated ambipolar electrical conduction in thin-film transistors based on amorphous conjugated polymers. Appl. Phys. Lett. 78, 228-230 (2001). Street, R. A., Northrup, J. E. \& Salleo, A. Transport in polycrystalline polymer thin-film transistors. Phys. Rev. B 71, 165202 (2005). Noriega, R. et al. A general relationship between disorder, aggregation and charge transport in conjugated polymers. Nat. Mater. 12, 1037-1043 (2013). Zhan, C. G., Nichols, J. A. \& Dixon, D. A. Ionization potential, electron affinity, electronegativity, hardness, and electron excitation energy: Molecular properties from density functional theory orbital energies. J. Phys. Chem. A 107, 4184-4195 (2003). Duhm, S. et al. Orientation-dependent ionization energech Fadley, C. S. In : Bundle, C. R. , Baker, A. D., (Eds.), Electron Spectroscopy: Theory, Techniques and Applications, Academic Press, London, 1978.

Nielsen, C. B., Turbiez, M. \& McCulloch, I. Recent advances in the development of semiconducting DPP-containing polymers for transistor applications. Adv. Mater. 25, 18591880 (2013).

42 Wang, E. G. et al. An easily synthesized blue polymer for high-performance polymer solar cells. Adv. Mater. 22, 5240-5244 (2010).

43 Wang, Q. et al. Investigations of the conjugated polymers based on Dithienogermole (DTG) units for photovoltaic applications. Macromolecules 47, 5558-5565 (2014). performance of organic solar cell devices. J. Mater. Chem. 22, 15141-15145 (2012). 
Heeger, A. J. Charge storage and charge transport in conducting polymers - solitons, polarons and bipolarons. Philos. T. R. Soc. A 314, 17-35 (1985).

Suzuki, N., Ozaki, M., Etemad, S., Heeger, A. J. \& Macdiarmid, A. G. Solitons in polyacetylene - effects of dilute doping on optical-absorption spectra. Phys. Rev. Lett. 45, 1209-1213 (1980).

Salaneck, W. R., Friend, R. H. \& Bredas, J. L. Electronic structure of conjugated polymers: consequences of electron-lattice coupling. Phys. Rep. 319, 232-251 (1999). Su, W. P. \& Schrieffer, J. R. Soliton dynamics in polyacetylene. PNAS 77, 5626-5629 (1980). Fesser, K., Bishop, A. R. \& Campbell, D. K. Optical-absorption from polarons in a model of polyacetylene. Phys Rev B 27, 4804-4825 (1983).

Fahlman, M. Experimental amd Theroretical Studies of Organic Molecules for Electronic Devices Linköping University Ph. D thesis (1995).

lucci, G., Xing, K., Logdlund, M. \& FahIman, M. Polaron to bipolaron transition in a conjugated polymer - Rubidium-doped poly(P-Phenylenevinylene). Chem. Phys. Lett. 244, 139-144 (1995).

Cook, S., Furube, A. \& Katoh, R. Analysis of the excited states of regioregular polythiophene P3HT. Energ Environ Sci 1, 294-299 (2008).

Woo, H. S. et al. Photoinduced Absorption and Photoluminescence in Poly(2,5-DimethoxyP-Phenylene Vinylene). Phys Rev B 46, 7379-7389 (1992).

Cahen, D., Kahn, A. \& Umbach, E. Energetics of molecular interfaces. Mater Today 8, 32-41 (2005).

Heimel, G., Romaner, L., Zojer, E. \& Bredas, J. L. The interface energetics of self-assembled monolayers on metals. Accounts Chem. Res. 41, 721-729 (2008).

Crispin, X. et al. Characterization of the interface dipole at organic/metal interfaces. J. Am. Chem. Soc. 124, 8131-8141 (2002).

Vazquez, H., Flores, F. \& Kahn, A. Induced density of states model for weakly-interacting organic semiconductor interfaces. Org. Electron. 8, 241-248 (2007).

Chen, Y. C., Cunningham, J. E. \& Flynn, C. P. Dependence of rare-gas-adsorbate dipolemoment on substrate work function. Phys. Rev. B 30, 7317-7319 (1984).

Xu, Z., Chen, L.-M., Chen, M.-H., Li, G. \& Yang, Y. Energy level alignment of poly(3hexylthiophene): [6,6]-phenyl C[sub 61] butyric acid methyl ester bulk heterojunction. Appl. Phys. Lett. 95, 013301 (2009).

Sehati, P. et al. Energy-level alignment at metal-organic and organic-organic interfaces in bulk-heterojunction solar cells. IEEE J. Sel. Top. Quant. 16, 1718-1724 (2010). Osikowicz, W., de Jong, M. P. \& Salaneck, W. R. Formation of the interfacial dipole at organic-organic interfaces: C60/polymer interfaces. Adv. Mater. 19, 4213 (2007). Bokdam, M., Cakir, D. \& Brocks, G. Fermi level pinning by integer charge transfer at electrode-organic semiconductor interfaces. Appl. Phys. Lett. 98, 113303 (2011). Braun, S., Osikowicz, W., Wang, Y. \& Salaneck, W. R. Energy level alignment regimes at hybrid organic-organic and inorganic-organic interfaces. Org. Electron. 8, 14-20 (2007). Braun, S., Liu, X., Salaneck, W. R. \& FahIman, M. Fermi level equilibrium at donor-acceptor interfaces in multi-layered thin film stack of TTF and TCNQ. Org. Electron. 11, 212-217 (2010).

Ley, L., Smets, Y., Pakes, C. I. \& Ristein, J. Calculating the universal energy-level alignment of organic molecules on metal oxides. Adv. Funct. Mater. 23, 794-805 (2013). Oehzelt, M., Koch, N. \& Heimel, G. Organic semiconductor density of states controls the energy level alignment at electrode interfaces. Nat. Commun. 5, 4174 (2014). Brocks, G., Cakir, D., Bokdam, M., de Jong, M. P. \& Fahlman, M. Charge equilibration and potential steps in organic semiconductor multilayers. Org. Electron. 13, 1793-1801 (2012). Cakir, D., Bokdam, M., de Jong, M. P., Fahlman, M. \& Brocks, G. Modeling charge transfer at organic donor-acceptor semiconductor interfaces. Appl. Phys. Lett. 100, 203302 (2012). 
70 Arkhipov, V. I., Heremans, P. \& Bassler, H. Why is exciton dissociation so efficient at the interface between a conjugated polymer and an electron acceptor? Appl. Phys. Lett. 82, 4605-4607 (2003).

71 Vazquez, H. et al. Barrier formation at metal-organic interfaces: dipole formation and the charge neutrality level. Appl. Surf. Sci. 234, 107-112 (2004).

72 Vazquez, H., Gao, W., Flores, F. \& Kahn, A. Energy level alignment at organic heterojunctions: Role of the charge neutrality level. Phys. Rev. B 71, 041306 (2005). Vazquez, H. et al. Dipole formation at metal/PTCDA interfaces: role of the charge neutrality level. Europhys. Lett. 65, 802-808 (2004).

74 Salzmann, I. et al. Intermolecular hybridization governs molecular electrical doping. Phys. Rev. Lett. 108, 035502 (2012). Mendez, H. et al. Doping of organic semiconductors: impact of dopant strength and electronic coupling. Angew. Chem. Int .Edit. 52, 7751-7755 (2013). 24, 6439-6448 (2014). Shen, C., Kahn, A. \& Schwartz, J. Chemical and electrical properties of interfaces between magnesium and aluminum and tris-(8-hydroxy quinoline) aluminum. J. Appl. Phys. 89, 449459 (2001).

Fahlman, M. et al. Electronic-structure of pristine and sodium-doped cyano-sbstituted ply(2,5-Dihexyloxy-p-penylenevinylene) - a combined experimental and theoretical-study. J. Chem. Phys. 102, 8167-8174 (1995).

79 Feng, X. F. et al. Electronic structures and chemical reactions at the interface between Li and regioregular poly (3-hexylthiophene). Org. Electron. 13, 1060-1067 (2012). Hufner, S. Photoelectron Spectroscopy: Principles and Applications 3rd, Springer-Verlag, 2003.

Svensson, S., Eriksson, B., Martensson, N., Wendin, G. \& Gelius, U. Electron shake-up and correlation satellites and continuum shake-off distributions in X-ray photoelectron-spectra of the rare-gas atoms. J. Electron. Spectrosc. Relat. Phenom. 47, 327-384 (1988). Tillborg, H., Nilsson, A. \& Martensson, N. Shake-up and shake-off structures in core-level photoemission spectra from adsorbates. J. Electron. Spectrosc. Relat. Phenom. 62, 73-93 (1993).

83 Lindau, I. \& Spicer, W. E. The probing depth in photoemission and auger-electron spectroscopy. J. Electron. Spectrosc. Relat. Phenom. 3, 409 (1974).

84 Farchioni, R. \& Grosso, G. E. Organic Electronic Materials: Conjugated Polymers and Low Molecular Weight Organic Solids. Springer (2001).

Meyer, J. et al. Charge generation layers comprising transition metal-oxide/organic interfaces: Electronic structure and charge generation mechanism. Appl. Phys. Lett. 96, 193302 (2010). polyfluorene and fluorene-arylamine copolymers at interfaces. J. Phys. Chem. C 111, 13781384 (2007).

87 Zahn, D. R. T., Gavrila, G. N. \& Gorgoi, M. The transport gap of organic semiconductors studied using the combination of direct and inverse photoemission. Chem. Phys. Lett. 325, 99-112 (2006).

88 Salaneck, W. R., Logdlund, M., Fahlman, M., Greczynski, G. \& Kugler, T. The electronic structure of polymer-metal interfaces studied by ultraviolet photoelectron spectroscopy. Mat. Sci. Eng. R. 34, 121-146 (2001).

89 Lin, T. C., Seshadri, G. \& Kelber, J. A. A consistent method for quantitative XPS peak analysis of thin oxide films on clean polycrystalline iron surfaces. Appl. Surf. Sci. 119, 83-92 (1997). 
Sekine, T., Ikeo, N. \& Nagasawa, Y. Comparison of AES chemical shifts with XPS chemical. Appl. Surf. Sci. 100, 30-35 (1996).

Bao, Q. Y., Yang, J. P., Li, Y. Q. \& Tang, J. X. Electronic structures of MoO3-based charge generation layer for tandem organic light-emitting diodes. Appl. Phys. Lett. 97, 063303 (2010).

Seah, M. P. \& Dench, W. A. Quantitative electron spectroscopy of surfaces: a standard data base for electron inelastic mean free paths in solids. Surf. Interface Anal. 1, 2-11 (1979).

94 Kanai, K. et al. Effect of annealing on the electronic structure of poly(3-hexylthiophene) thin film. Phys. Chem. Chem. Phys. 12, 273-282 (2010). hybrid solar cells. Energ. Environ. Sci. 5, 8045-8074 (2012). characterization and charge transport in thin films of conjugated polymers. Adv. Mater. 22, 3812-3838 (2010). (1959).

99 Tang, C. W. Two-layer organic photovoltaic cell. Appl. Phys. Lett. 48, 183 (1986).

100 Halls, J. J. M., Pichler, K., Friend, R. H., Moratti, S. C. \& Holmes, A. B. Exciton diffusion and dissociation in a poly(p-phenylenevinylene)/C60 heterojunction photovoltaic cell. Appl. Phys. Lett. 68, 3120 (1996).

101 Stubinger, T. \& Brutting, W. Exciton diffusion and optical interference in organic donoracceptor photovoltaic cells. J. Appl. Phys. 90, 3632-3641 (2001).

102 Blom, P. W. M., Mihailetchi, V. D., Koster, L. J. A. \& Markov, D. E. Device physics of polymer : fullerene bulk heterojunction solar cells. Adv. Mater. 19, 1551-1566 (2007).

103 Gunes, S., Neugebauer, H. \& Sariciftci, N. S. Conjugated polymer-based organic solar cells. Chem. Rev. 107, 1324-1338 (2007).

104 Hiramoto, M., Fujiwara, H. \& Yokoyama, M. 3-Layered Organic Solar-Cell with a Photoactive Interlayer of Codeposited Pigments. Appl Phys Lett 58, 1062-1064 (1991).

105 Lu, L. Y., Xu, T., Chen, W., Landry, E. S. \& Yui, L. P. Ternary blend polymer solar cells with enhanced power conversion efficiency. Nat. Photon. 8, 716-722 (2014).

106 Lai, T. H., Tsang, S. W., Manders, J. R., Chen, S. \& So, F. Properties of interlayer for organic photovoltaics. Mater. Today 16, 424-432 (2013).

107 He, Z. C. et al. Enhanced power-conversion efficiency in polymer solar cells using an inverted device structure. Nat Photonics 6, 591-595 (2012).

108 Shockley, W. \& Queisser, H. J. Detailed balance limit of efficiency of p-n junction solar cells. J. Appl. Phys. 32, 510 (1961).

109 You, J. B., Dou, L. T., Hong, Z. R., Li, G. \& Yang, Y. Recent trends in polymer tandem solar cells research. Prog. Polym. Sci. 38, 1909-1928 (2013).

110 Bredas, J. L., Cornil, J. \& Heeger, A. J. The exciton binding energy in luminescent conjugated polymers. Adv. Mater. 8, 447 (1996).

111 Drori, T. et al. Below-gap excitation of pi-conjugated polymer-fullerene blends: Implications for bulk organic heterojunction solar cells. Phys. Rev. Lett. 101, 037401 (2008).

112 Clarke, T. M. \& Durrant, J. R. Charge photogeneration in organic solar cells. Chem. Rev. 110, 6736-6767 (2010).

113 Zhu, X. Y., Yang, Q. \& Muntwiler, M. Charge-transfer excitons at organic semiconductor surfaces and interfaces. Accounts Chem. Res. 42, 1779-1787 (2009).

114 Vandewal, K., Tvingstedt, K., Gadisa, A., Inganas, O. \& Manca, J. V. On the origin of the open-circuit voltage of polymer-fullerene solar cells. Nat. Mater. 8, 904-909 (2009). 
115 Vandewal, K. et al. Efficient charge generation by relaxed charge-transfer states at organic interfaces. Nat. Mater. 13, 63-68 (2014).

116 Groves, C. \& Greenham, N. C. Bimolecular recombination in polymer electronic devices. Phys. Rev. B 78, 155205 (2008).

117 Chen, S. et al. Inverted polymer solar cells with reduced interface recombination. Adv. Energy Mater. 2, 1333-1337 (2012). 


\section{Publications}




\section{Publications}

The articles associated with this thesis have been removed for copyright reasons. For more details about these see:

http://urn.kb.se/resolve?urn=urn:nbn:se:liu:diva-118922 